\title{
PATRIMONIO INDUSTRIAL RURAL DE TERUEL: UN EJEMPLO DE ABANDONO DEL TERRITORIO
}

\author{
Luis del Romero Renau \\ Departament de Geografia. Universitat de València \\ Luis.Romero@uv.es \\ Antonio Valera Lozano \\ Departament de Geografia. Universitat de València \\ Antonio.valera@uv.es \\ Neus La Roca Cervigón \\ Departament de Geografia. Universitat de València \\ Neus.la.roca@uv.es
}

\begin{abstract}
Resumen: El objetivo de este artículo es analizar la naturaleza, distribución, importancia y el estado del patrimonio industrial disperso de la provincia de Teruel que cumpla los siguientes criterios: estar fuera de núcleos de población, estar abandonado, no estar completamente asolado y otros. Se han explorado múltiples fuentes: cartografía histórica; publicaciones, bases de datos (archivos, SIPCA, etc.); contactos mediante redes sociales y varias entrevistas. Con la información obtenida se ha realizado un análisis mediante SIG. En conclusión, el número de industrias abandonadas o destruidas es ingente en números absolutos y en comparación con lo restaurado. El trabajo amplia y actualiza parte del SIPCA, y reflexiona sobre la situación de abandono del importante patrimonio que conforman molinos, batanes, minas y fábricas en este territorio. Faltan herramientas de protección y concienciación sobre un patrimonio único e irrepetible.
\end{abstract}

Palabras clave: Patrimonio industrial, provincia de Teruel, abandono.

Abstract: The aim of this paper is the analysis of the scattered industrial heritage in Teruel that meets the following criteria: located out of an urban center, not totally abandoned and other criteria. Multiple data have

Recibido: 28-03-18. Aceptado: 15-11-18. 
been explored: historic cartography; publications, databases (archives, SIPCA, etc.); social media contacts and some interviews. With the information obtained, a GIS analysis has been carried out. In conclusion, the number of industries abandoned or destroyed is huge in absolute numbers and comparing it to remaining industrial sites. The work expands and updates part of the SIPCA heritage information system, and reflects on the situation of abandonment of the important heritage that make mills, mines and factories in this territory. Tools of protection and awareness of a unique and unrepeatable heritage are lacking.

Keywords: Industrial heritage, province of Teruel, rural decline.

\section{Introducción}

El estudio del patrimonio industrial es una línea de investigación relativamente reciente en España, que normalmente se concentra en la resignificación de los antiguos espacios industriales como nuevas oportunidades de desarrollo turístico (Pardo Abad, 2010; Cañizares Ruiz, 2011), si bien otros autores amplían esta visión a su triple condición de recurso, memoria del lugar y seña de identidad colectiva (Benito del Pozo, 2002).

El concepto de patrimonio no siempre ha tenido la misma acepción que en la actualidad. Según Claver y Sebastián (2016), desde su significado inicial como conjunto de bienes o posesiones que otorga beneficios de poder o económicos, ha acumulado contenidos hasta su concepción más moderna de bienes valiosos para la sociedad desde varios puntos de vista (artístico, económico, etc.) cuya conservación se entiende necesaria aunque pueda suponer un coste. En el siglo XX han ido progresivamente siendo incluidos como patrimonio los bienes industriales que destacaban por su singularidad técnica o por su contribución al desarrollo y configuración de un modelo social o territorial particulares. No obstante, la percepción por la sociedad española de ese valor patrimonial de elementos a veces sucios, destartalados y vinculados a conflictos sociales y a profundas crisis económicas, ha sido lenta y difícil hasta fechas relativamente cercanas (Pardo Abad, 2016).

Según dicta la Ley de Patrimonio histórico español "La protección y el enriquecimiento de los bienes que lo integran constituyen obligaciones fundamentales que vinculan a todos los poderes públicos, según el mandato que a los mismos dirige el artículo 46 de la norma constitucional.” (Ley 16/1985, de 25 de junio, del Patrimonio Histórico Español). Dicha Ley "Busca, en suma, asegurar la protección y fomentar la cultura material debida a la acción del hombre en sentido amplio, y concibe aquélla como un conjunto de bienes que en si mismos han de ser apreciados, sin establecer limitaciones derivadas de su propiedad, uso, antigüedad o valor económico". Además, el preámbulo de la ley señala "...la defensa del Patrimonio Histórico de un pueblo no debe realizarse exclusi- 
vamente a través de normas que probíban determinadas acciones o limiten ciertos usos, sino a partir de disposiciones que estimulen a su conservación y, en consecuencia, permitan su disfrute y faciliten su acrecentamiento".

Por su parte, el Plan Nacional de Patrimonio Industrial de 2001 aporta una definición propia y el factor riesgo en la valoración y priorización de aquellos elementos que se encuentren en situación de mayor urgencia. El plan identifica como patrimonio industrial en esa definición a los elementos relacionados con la actividad productiva entre mediados del s. XVIII y el último tercio del s. XX.

No todo el mundo asocia a Teruel con un territorio minero e industrial, sin embargo esta provincia durante un tiempo, sobre todo antes, pero también durante las grandes revoluciones industriales, fue un gran centro minero, textil y de producción de alimentos. Unos pocos datos pueden sorprender al lector. Durante algunos años en esta provincia estuvo la mina de azufre más importante del país (Libros), la central térmica de mayor producción (Aliaga), una de las primeras y principales fábricas de papel-moneda del Estado (Villarluengo) (Salillas, 2008), la mina de carbón a cielo abierto más grande de España (Ariño), la línea de ferrocarril minero más larga (Ojos Negros a Puerto de Sagunto) (Asociación de Amigos de Sierra Menera, 2009), o una de las industrias azucareras más destacadas del país (Santa Eulalia). La riqueza y variedad de este patrimonio motivó que la ley del 3/1999 de 10 de marzo de Patrimonio Cultural Aragonés cuente con un título especialmente orientado a los bienes de naturaleza industrial. No obstante, no abundan los estudios que lo analicen a una escala provincial, ni siquiera por grupos de grandes actividades industriales o protoindustriales: molinería, fabricación textil o minería, si bien hay que mencionar algunos como las investigaciones de $\mathrm{M}^{\mathrm{a}}$ Pilar Biel sobre el patrimonio industrial eléctrico (Biel, 2011), minero (Biel, 2012) y documental (Biel, 2016) en Aragón. Aparte de esos trabajos, que hacen especial hincapié en el patrimonio industrial urbano, el único esfuerzo serio de inventario y sistematización de este tipo de patrimonio realizado hasta la fecha se halla en el Sistema de Inventario de Patrimonio Cultural Aragonés (DPH, 2017), con muchas referencias procedentes de un estudio de hace década y media (Biel, 2004), así como diversas publicaciones divulgativas a escala comarcal en Aragón surgidas tras el proceso de comarcalización en 2003, que tratan el estudio el patrimonio industrial turolense de manera tangencial.

\section{Hipótesis y objetivos}

El territorio turolense alojó fuera de los núcleos de población una actividad industrial, digna de mención por su variedad y magnitud, que ha caído en el olvido. Las construcciones destinadas a dichas actividades, con sus dependencias y toda o parte de la maquinaria que sirvieron al proceso productivo, constituyen hoy un patrimonio histórico industrial de primer orden a partir del cual todavía se puede reconstruir su con- 
tribución "a la cultura universal". Para proteger ese patrimonio es necesario conocerlo, evaluar su interés histórico-cultural, su estado de conservación y su aportación a la cultura, en general, y geográfica, en particular. Es también importante establecer líneas futuras de trabajo para una mejor gestión de este patrimonio.

El objetivo de este trabajo es por tanto analizar la naturaleza, distribución geográfica, importancia provincial y por comarcas, y el estado de conservación y restauración del patrimonio industrial disperso de la provincia de Teruel. Dado que el conjunto patrimonial de la provincia es muy vasto, ha sido necesario establecer criterios estrictos de selección que permitan discriminar su inclusión o no en este trabajo. Esos criterios se detallan en el apartado de metodología.

Este trabajo tiene además dos objetivos específicos relativos a la dimensión histórico-geográfica y cultural del patrimonio analizado y a la capacidad de estos elementos para transmitirla:

- Realizar un análisis histórico de los ciclos y actividades industriales no urbanas en la provincia de Teruel.

- Proponer posibles líneas de actuación para la protección del patrimonio industrial abandonado disperso de la provincia de Teruel.

\section{Metodología}

Como ya se ha indicado en la introducción la cantidad y variedad de patrimonio industrial turolense es ingente. El inventario que se presenta en este trabajo no pretende ser oficial ni englobar la totalidad de elementos a proteger. De cara a su inventario y caracterización para su análisis geográfico, histórico y propuestas de alternativas de recuperación, se han aplicado los siguientes criterios de selección:

1) Ubicación fuera de núcleo urbano, más allá de una distancia mínima de 50 metros respecto al borde urbano consolidado. Se aplica para garantizar el carácter rural de los elementos, entendido este no por su funcionalidad sino por su localización fuera de áreas urbanas. El patrimonio disperso suele ser el más vulnerable y menos estudiado en la mayor parte de los casos puesto que, pese a no verse amenazado por los procesos de crecimiento urbano, queda fuera del ámbito de control y vigilancia de la mayor parte de la población. Los núcleos han experimentado un crecimiento urbano y elementos que en origen estaban claramente fuera, hoy están casi asimilados. La distancia mínima de 50 metros respecto al borde urbano consolidado asume que a ésta se le suma la correspondiente ampliación del borde urbano, mucho más alejado en el momento de actividad del elemento que en la actualidad. 
2) En estado de abandono, degradación o cerrados por fin de actividad. Atendiendo a la variable de riesgo que incorpora el propio Plan Nacional, no se han incluido complejos industriales en funcionamiento al considerar que la propia actividad debería garantizar el mantenimiento de los mismos, si bien estas casuísticas son testimoniales en la provincia.

3) No rehabilitados como vivienda o para otro uso. Se han excluido, en general, los elementos totalmente transformados, reedificados o destinados a un uso actual residencial o turístico. El motivo es, de nuevo, priorizar la identificación de elementos en riesgo. No obstante, algunas muestras excepcionales que albergan otro uso, sí son incluidas en el análisis como ejemplos de propuestas de recuperación exitosas, siempre y cuando no hayan perdido su fisonomía original.

4) Se ha considerado que los elementos en ruinas se han alejado también de forma significativa de su estado inicial y difícilmente son susceptibles de degradarse mucho más y que en ese caso queda reducida significativamente la variable riesgo. No se incluyen, en general, elementos que hayan perdido totalmente su tejado, estructura y maquinaria original, al considerarse reducido significativamente su valor como patrimonio inmueble y mueble y su capacidad de transmitir información sobre la actividad (Claver y Sebastián, 2016).

En líneas generales, solo cuando cumplen estos cuatro requisitos, se han visitado los elementos identificados. No obstante, se añadieron unos requisitos que abren el análisis de campo a casos especiales con:

5) Especial interés por conservar patrimonio mueble en buen estado o por su importancia inmaterial para la sociedad local, o, por último, con falta de información para decidir su inclusión/exclusión definitivas.

A fin de clarificar qué se entendía aquí como elemento industrial, y para estructurar mejor el análisis y caracterización posteriores, se elaboró una clasificación jerárquica. Pese a que en muchos catálogos los molinos y otros artilugios hidráulicos (martinetes, batanes, etc.) se consideran elementos preindustriales, se decidió incluirlos en el análisis porque puede considerarse que entran en la definición propuesta por el Plan Nacional y porque al haber mantenido su actividad hasta el segundo o el tercer tercio del siglo XX, es ahora cuando muchos de ellos corren serio peligro de desaparición. La categorización propuesta responde a criterios funcionales, permitiéndonos distinguir entre elementos para la transformación del producto agrícola de cara a un consumo local y/o regional; de las fábricas para la producción de bienes comerciales más allá de lo comunal; de instalaciones para la producción de energía; la industria extractiva comercial que incluya un mínimo de procesamiento del producto y, por último, la industria de bienes destinados a la construcción. Mención aparte merecen las peguerías. Aunque otras clasificaciones incorporan más categorías fabriles, el carácter rural del territorio 
analizado deja fuera a muchas de ellas a la vez que exige profundizar en otras. Esta clasificación sufrió una continua revisión y adaptación conforme se avanzaba en el trabajo, y se hacían descubrimientos como, por ejemplo, que por lo habitual un antiguo molino puede acabar convertido en fábrica de harinas, ampliando maquinaria y suministro de energía, o en fábrica de luz al diversificar sus funciones por aumento de la demanda eléctrica. Finalmente se establecieron cinco clases principales que se subdividen en otras veinte categorías más detalladas:

1. Molinos

1.0. Molino (indiferenciado)

1.1. Molino harinero

1.2. Molino de aceite/almazara

2. Fábricas y batanes

2.0. Fábrica o batán (indiferenciada)

2.1. Harinera

2.2. Batán o fábrica textil

2.3. Papelera

2.4. Fábrica de sulfuro/jabón

2.5. Otras fábricas (serrerías, martinetes, herrerías, chocolaterías, etc.)

3. Producción eléctrica

3.0. Producción eléctrica (indiferenciada)

3.1. Fábrica de luz

3.2. Central eléctrica

4. Extracción y transformación minera

4.0. Mina (indiferenciada)

4.1. Minas de carbón

4.2. Salina

4.3. Otras minas (azufre, etc.)

5. Otros elementos industriales

5.0. Otros elementos industriales (indiferenciados)

5.1. Tejería

5.2. Yesería

5.3. Casas o almacenes de resineros 
Como puede apreciarse en esta clasificación, se han incluido las zonas de extracción minera, siempre y cuando incorporaran algún tipo de patrimonio inmueble y mueble de transformación, refinado, almacenaje, etc.. Así, tanto para las minas como para otras actividades de aprovechamiento directo de recursos (por ejemplo peguerías), se estableció como condición para su inclusión en este trabajo, que existiera algún edificio o espacio físico identificable para esas labores de almacenaje, transformación, etc.

Partiendo de esos criterios y categorías de elementos a incluir en el trabajo, se ha realizado una ardua tarea de búsqueda, identificación y selección inicial de los elementos de industria dispersa abandonada en Teruel. Para ello se han utilizado cinco fuentes principales:

- Cartografía topográfica histórica del CNIG-IGN. Han sido de gran utilidad en este trabajo los mapas topográficos históricos elaborados desde los años 20 del siglo XX hasta la actualidad. Las primeras ediciones muestran con gran detalle y profusión las construcciones industriales (molinos, fábricas, tejerías, etc.) que articulaban los territorios rurales y que actualmente se encuentran en muchos casos desparecidos.

- Bases de datos o catálogos de consulta pública. A nivel regional, comarcal o municipal diferentes bases de datos han sido utilizadas en este trabajo:

- Sistema de Información del Patrimonio Cultural de Aragón SIPCA. Aunque es la más amplia fuente de información sobre patrimonio en la región y está en continua ampliación, presenta algunos problemas en cuanto a cantidad, calidad y actualización, especialmente en ciertas áreas geográficas o con aquellos elementos de más difícil localización o accesibilidad.

- Xilocapedia. Recoge bastante información sobre elementos industriales de la comarca del Jiloca, incluyendo su localización y publicaciones relacionadas.

- Catálogo artístico y monumental de la Fundación Quíllez Listérriz. Reúne una serie de fichas sobre patrimonio cultural para las comarcas de Matarranya, Bajo Aragón, Bajo Martín, Andorra-Sierra de Arcos y Maestrazgo.

- Archivo de la Diputación de Teruel. Aunque no es un catálogo específico sobre patrimonio industrial, se han consultado diferentes documentos, fotos y planos históricos de gran interés sobre proyectos, conflictos, procesos legales, etc. relacionados con la temática.

A partir de estas fuentes, complementado con la consulta de publicaciones locales sobre patrimonio, y consultas a entidades locales y asociaciones, se elaboró, en una primera fase en gabinete, una base de datos inicial con todos aquellos elementos de patrimonio que cumplían con los criterios establecidos en este trabajo. Todos los elementos identificados en la selección previa fueron georreferenciados mediante Sistemas de Información Geográfica (SIG) sobre cartografía detallada y/o ortofotos de alta resolución espacial. A fin de establecer una caracterización geográfica de las diferentes tipologías de industria ru- 
ral dispersa, los elementos georreferenciados fueron cruzados en un SIG con información geográfica básica. El cruce de información permitió establecer la frecuencia en que determinadas categorías de elementos se distribuían geográficamente según rangos de altitud, distancia, etc, aunque en este trabajo solo se ofrecen resultados generales.

El último paso fue elaborar de manera sintética, y a partir de las fuentes señaladas anteriormente, un análisis histórico destacando los elementos más reseñables. Para ello se realizó un filtrado de la base de datos inicial para establecer aquellos que serían visitados en campo y caracterizados mediante una ficha temática. Tras aproximadamente dos años de trabajo de campo por toda la provincia de Teruel, se elaboró una base de datos derivada y se caracterizaron todos aquellos elementos que cumplían los criterios de selección y valoración establecidos. La visita in situ permitió comprobar, por ejemplo, que muchos elementos estaban considerablemente más degradados de lo señalado en la fuentes o que contaban con interesante patrimonio mueble ignorado en los catálogos oficiales y las descripciones documentales.

De cara a obtener información sobre la componente inmaterial de este patrimonio se diseñó un modelo de entrevista semiestructurada que se aplicó sobre población local, antiguos molineros, operarios de fábrica, etc. y que permitió recomponer la cotidianidad técnica y socioeconómica en los elementos patrimoniales en sus momentos de máximo uso. También se entrevistó a entidades o personas que habían puesto en marcha proyectos de recuperación patrimonial exitosos.

\section{Resultados y discusión}

\subsection{Análisis geográfico del patrimonio industrial rural de la provincia de Teruel}

\subsubsection{Mapa del patrimonio industrial}

En líneas generales, se observa una estrecha relación entre la red hidrográfica de la provincia y la localización del patrimonio industrial identificado (Figura 1). Los mapas traducen la importancia de las corrientes de agua en las actividades protoindustriales e industriales de la provincia de Teruel, bien como fuerza motriz de maquinaria antes de la generalización del vapor y el gasoil, o bien por el consumo de agua para muchos de los procesos industriales de lavado, purificación, etc. Es casi indisociable, con algunas excepciones, la vinculación entre generación hidroeléctrica y la introducción de maquinaria eléctrica.

En segundo lugar, tomando el número y naturaleza de los elementos del patrimonio histórico industrial como indicativo de la dimensión del pasado industrial turolense, comentado en el punto 3.2, se aprecia una clara desigualdad comarcal del desarrollo industrial (Tabla 1). Así, mientras Gúdar-Javalambre acoge entre sus límites cerca de un 


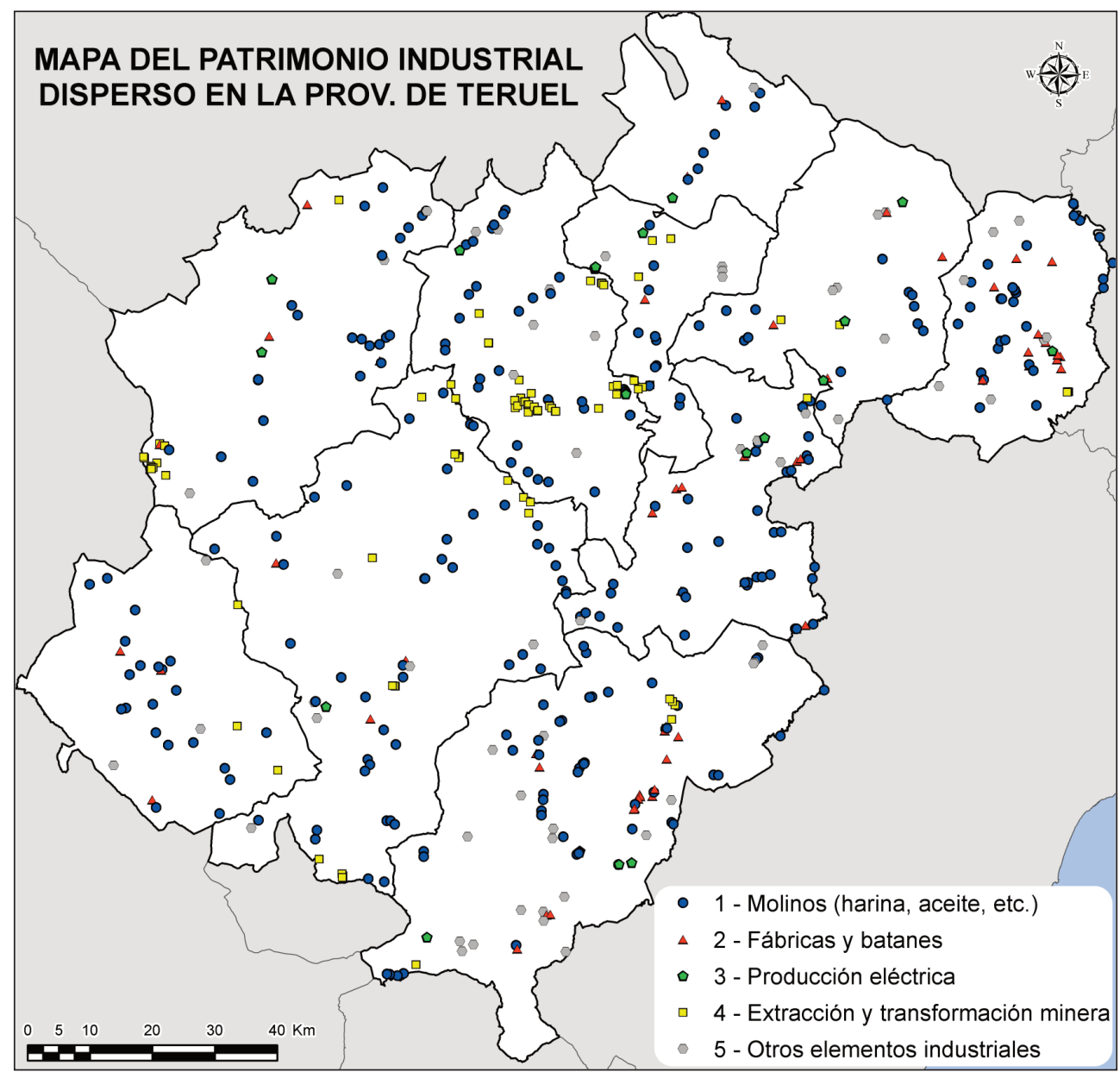

Figura 1. Mapa general de la industria dispersa en la provincia de Teruel.

Fuente: Elaboración propia.

centenar de localizaciones industriales, la comarca de Bajo Martín apenas supera los once elementos. Entre ambos extremos podemos situar las comarcas de Maestrazgo, La Matarranya y Jiloca, con entre 40 y 60 elementos cada una, y las de Bajo Aragón, Andorra-Sierra de Arcos y Sierra de Albarracín, con entre 25 y 30 emplazamientos.

Analizando la distribución de las distintas categorías queda evidenciada una de las razones de la fuerte relación entre la industria rural dispersa y la red hidrográfica: del casi medio millar de elementos identificados, más de la mitad corresponde a molinos, la mayor parte de ellos hidráulicos. Muy por detrás en cuanto a frecuencia se sitúan 
Tabla 1. Distribución por comarcas ( $n^{\circ}$ de elementos) del patrimonio industrial disperso

\begin{tabular}{|c|c|c|c|c|c|c|}
\hline COMARCA & 1-Molinos & $\begin{array}{l}\text { 2-Fábricas } \\
\text { o Batanes }\end{array}$ & $\begin{array}{c}\text { 3-Producción } \\
\text { eléctrica }\end{array}$ & $\begin{array}{c}\text { 4-Extraccción } \\
\text { ytransformación } \\
\text { minera }\end{array}$ & $\begin{array}{c}\text { 5-Otros } \\
\text { elementos } \\
\text { industriales }\end{array}$ & TOTAL \\
\hline $\begin{array}{l}\text { Exterior } \\
\text { (frontera con Castellón) }\end{array}$ & 2 & & & & & 2 \\
\hline Andorra - Sierra de Arcos & 11 & 1 & 4 & 6 & 4 & 26 \\
\hline Bajo Aragón & 13 & 4 & 2 & 2 & 6 & 27 \\
\hline Bajo Martín & 7 & 2 & 1 & & 1 & 11 \\
\hline Comunidad de Teruel & 45 & 3 & 1 & 20 & 6 & 75 \\
\hline Cuencas Mineras & 31 & & 3 & 34 & 7 & 75 \\
\hline Gúdar - Javalambre & 48 & 16 & 5 & 6 & 19 & 94 \\
\hline Jiloca & 23 & 4 & 2 & 11 & 3 & 43 \\
\hline Maestrazgo & 36 & 10 & 5 & 1 & 5 & 57 \\
\hline Matarraña / Matarranya & 30 & 12 & 1 & 3 & 8 & 54 \\
\hline Sierra de Albarracín & 21 & 3 & & 3 & 3 & 30 \\
\hline Total Provincia & 267 & 55 & 24 & 86 & 62 & 494 \\
\hline
\end{tabular}

Fuente: Elaboración propia.

las localizaciones de extracción y transformación minera (86 elementos), mucho menos vinculadas a la cercanía de cursos fluviales y dependientes, por el contrario, de las vetas o fuentes de mineral.

Los emplazamientos para la generación de energía, pese a ser relativamente poco frecuentes en relación a otros, jugaron un papel muy importante en el desarrollo regional y en las economías locales, siendo uno de los objetivos principales de los maquis durante la posguerra, como queda patente en los registros históricos provinciales. El resto de elementos industriales dispersos sumarían 62 localizaciones, que corresponderían principalmente con tejerías, yeserías y otras producciones básicas destinadas al consumo local y cuya localización viene marcada por la materia prima. A continuación se detalla este primer análisis con una aproximación por grandes sectores de actividad.

Se confirma, por tanto, la tendencia general en esas épocas de ubicar la industria bien junto a las fuentes de energía, o bien junto a la materia prima para minimizar costes de transporte en la producción. 
Tabla 2. Distribución ( $n^{\circ}$ de elementos) del patrimonio industrial disperso según altitud media, distancia a ríos principales y distancia a núcleos de población principales

\begin{tabular}{|c|c|c|c|c|c|c|c|}
\hline \multicolumn{2}{|c|}{ VARIABLE GEOGRÁFICA } & 1-Molinos & $\begin{array}{l}\text { 2-Fábricas } \\
\text { o Batanes }\end{array}$ & $\begin{array}{l}\text { 3-Producción } \\
\text { eléctrica }\end{array}$ & $\begin{array}{c}\text { 4-Extraccción } \\
\text { ytransformación }\end{array}$ & $\begin{array}{l}\text { 5-Otros } \\
\text { elementos }\end{array}$ & TOTAL \\
\hline \multirow{6}{*}{ 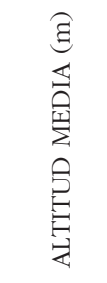 } & $<250$ & 3 & 3 & 0 & 0 & 0 & 0 \\
\hline & $250-500$ & 50 & 25 & 10 & 4 & 2 & 9 \\
\hline & $500-750$ & 77 & 37 & 11 & 11 & 8 & 10 \\
\hline & $750-1.000$ & 131 & 78 & 11 & 6 & 17 & 19 \\
\hline & $1.000-1.250$ & 139 & 72 & 17 & 2 & 36 & 12 \\
\hline & $1.250-1.500$ & 90 & 49 & 6 & 1 & 22 & 12 \\
\hline \multirow{6}{*}{ 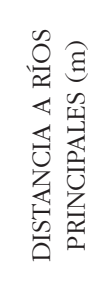 } & $0-250$ & 233 & 46 & 24 & 16 & 26 & 345 \\
\hline & $250-500$ & 16 & 5 & 0 & 11 & 6 & 38 \\
\hline & $500-1.000$ & 8 & 3 & 0 & 18 & 11 & 40 \\
\hline & $1.000-2.500$ & 8 & 0 & 0 & 40 & 19 & 67 \\
\hline & $2.500-5.000$ & 2 & 1 & 0 & 1 & 0 & 4 \\
\hline & $1>5.000$ & 0 & 0 & 0 & 0 & 0 & 0 \\
\hline \multirow{6}{*}{ 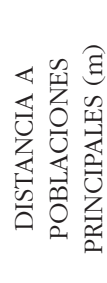 } & $0-250$ & 63 & 46 & 8 & 1 & 1 & 7 \\
\hline & $250-500$ & 34 & 21 & 1 & 3 & 4 & 5 \\
\hline & $500-1.000$ & 77 & 46 & 12 & 2 & 10 & 7 \\
\hline & $1.000-2.500$ & 208 & 106 & 26 & 11 & 44 & 21 \\
\hline & $2.500-5.000$ & 88 & 35 & 7 & 7 & 24 & 15 \\
\hline & $>5.000$ & 24 & 13 & 1 & 0 & 3 & 7 \\
\hline
\end{tabular}

Fuente: Elaboración propia.

\subsubsection{La molinería en la provincia de Teruel}

Como ya se ha indicado, los molinos representan un porcentaje importante de los elementos identificados. Se localizan principalmente en los ríos Mijares, Alfambra y Martín, si bien están presentes en la mayor parte del territorio provincial. Para aprovechar las aguas de los diferentes ríos que los alimentan, los molinos conectaban con éstos a través de acequias. Por ese motivo, casi el 90\% de los molinos identificados en este trabajo se encuentra a menos de 250 metros del cauce un río principal (ver Tabla 2). La provincia cuenta con numerosos cursos fluviales, pero generalmente escasos de caudal. Ello se resuelve construyendo junto a un mismo cauce hasta dos y tres molinos separados entre ellos pocos cientos de metros, para aprovechar al máximo, reutilizando, el caudal de agua necesario para mover los rodeznos. Existen multitud de cursos que 

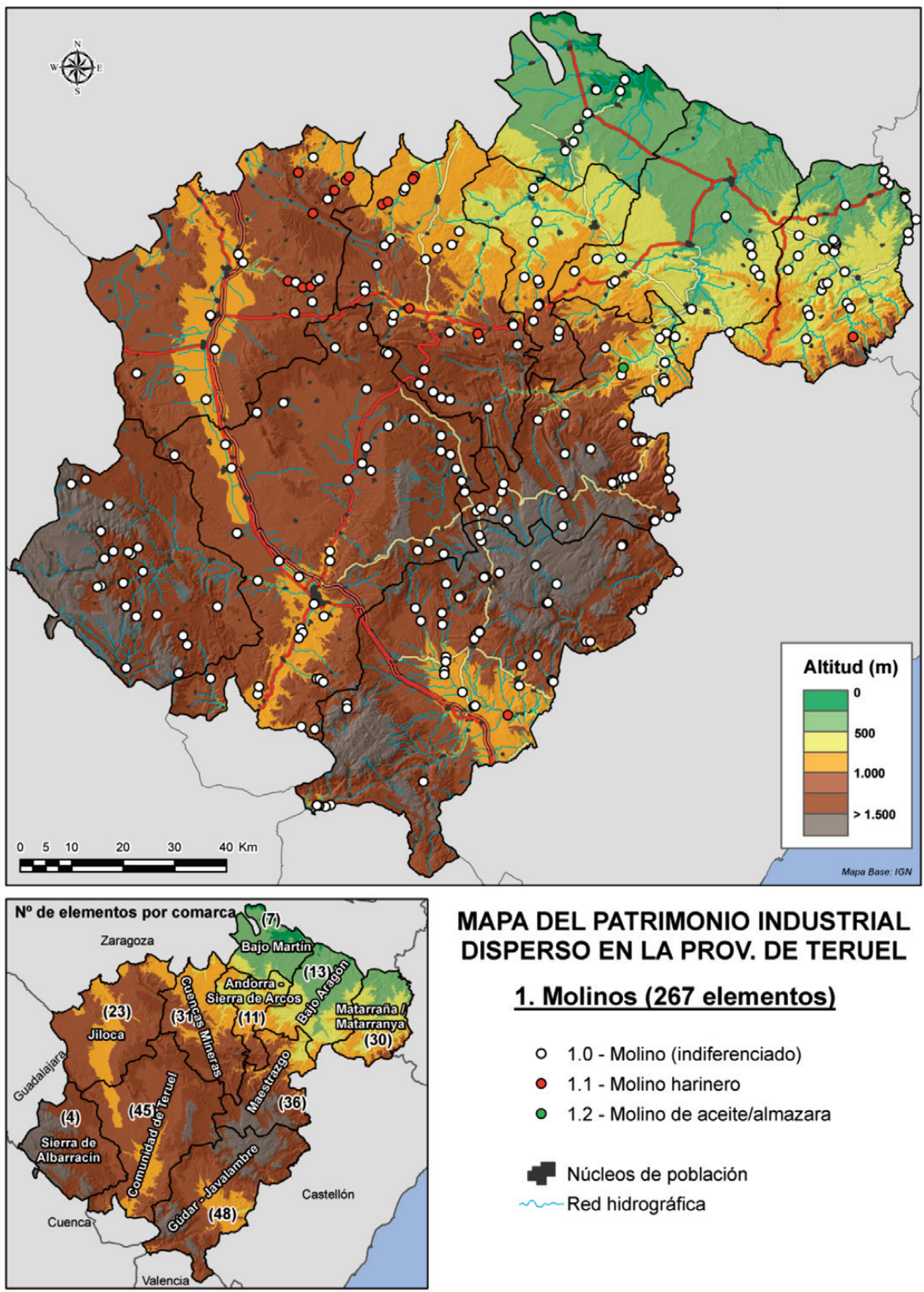

MAPA DEL PATRIMONIO INDUSTRIAL DISPERSO EN LA PROV. DE TERUEL

\section{Molinos (267 elementos)}

- 1.0 - Molino (indiferenciado)

- 1.1 - Molino harinero

- 1.2 - Molino de aceite/almazara

Núcleos de población

$\sim$ Red hidrográfica

Figura 2. Mapa de localización de molinos.

Fuente: Elaboración propia. 
cuentan con un Molino de Arriba, de Enmedio y de Abajo con un mismo fin. Además, la irregularidad de las precipitaciones hace que muchos años algunos molinos no puedan funcionar por no disponer de suficiente caudal para abastecer las balsas, lo que obliga a disponer de alternativas. En la comarca de Gúdar-Javalambre son especialmente apreciados los molinos ubicados junto al río Mijares por ser de los pocos de la comarca que disponen de caudal suficiente todo el año, mientras que muchos otros solamente pueden funcionar durante determinados meses.

Esa cercanía a los cursos ha supuesto posteriormente un importante factor de riesgo y degradación para los molinos. Avenidas catastróficas, humedades, caída/crecimiento de árboles o construcción de modernas infraestructuras de captación o regulación de aguas, han afectado a menudo a mucho de este patrimonio mueble e inmueble turolense.

Aunque resulta complicado establecer la tipología del molino a partir de muchas de las fuentes consultadas (sobre todo las cartográficas), otra documentación y las visitas de campo han permitido identificar un gran número de ellos como molinos harineros, especialmente en las comarcas del sur. Probablemente por analizar solo los molinos en el ámbito rural, la distancia a los núcleos de población no parece constituir un factor de localización tan relevante, situándose casi el 60\% a más de $1 \mathrm{~km}$ de los núcleos. Sin lugar a dudas, el molino harinero es no solo el elemento de patrimonio industrial más frecuente, sino también el que presenta una estructura más homogénea. La inmensa mayoría son molinos de balsa y cubo, con dos muelas, una de piensos y otra para la alimentación humana, que desagua al mismo río mediante uno o dos cárcavos. Tan solo los molinos ubicados junto a ríos principales como el Mijares, Guadalaviar o Jiloca podían tener suficiente caudal de agua todo el año, mientras que el resto funcionaba con balsas que se iban llenando con los aportes de ríos o acequias cuando había suficiente caudal.

Además de los molinos harineros, hay que mencionar la importancia de la molinería de aceites o almazaras en el Bajo Aragón y La Matarranya. Aunque muchas de estas fábricas estaban dentro de los núcleos urbanos y no se han contemplado en estudio, existen muchos ejemplos notables fuera de éstos, como la fábrica de aceites de Valdealgorfa o la fábrica de aceites de Fórnols, por citar solo dos ejemplos y que constituyeron la principal base económica de estos territorios (Bayod, 2009). Según cuenta uno de los entrevistados, antiguo trabajador de una de las almazaras en Fórnoles, se trataba de un trabajo duro, puesto que por un lado había que controlar a los machos que daban vueltas con los ojos tapados a la muela cónica que chafaba la oliva, ir aportando olivas poco a poco a la molienda, y por otro, entre varios hombres había que prensar el alperujo para extraer el máximo de aceite (Entrevista). 


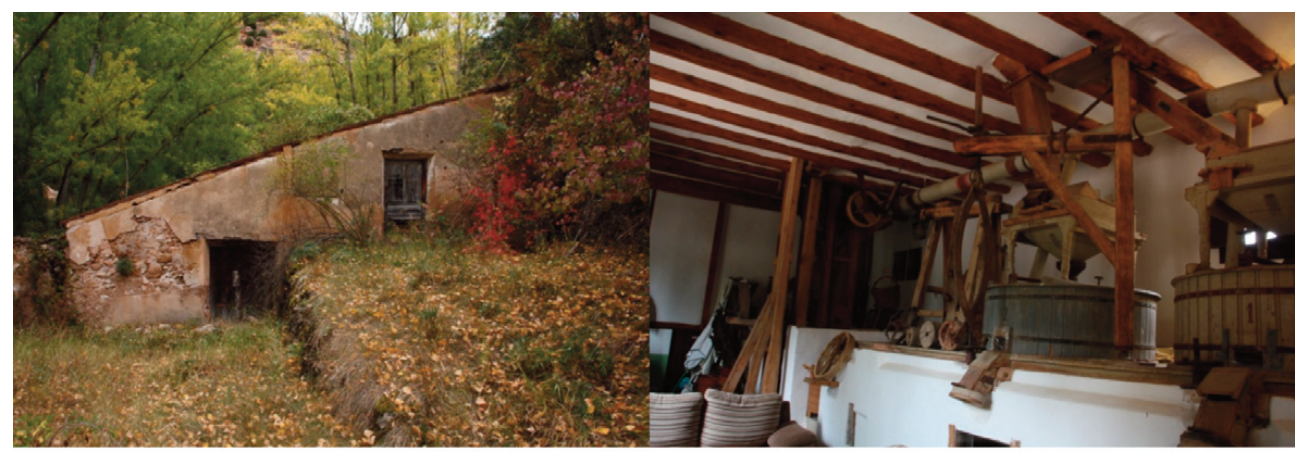

Figura 3. Molino Bajo de Ejulve.

Figura 4. Molino Bajo de Monreal del Campo.

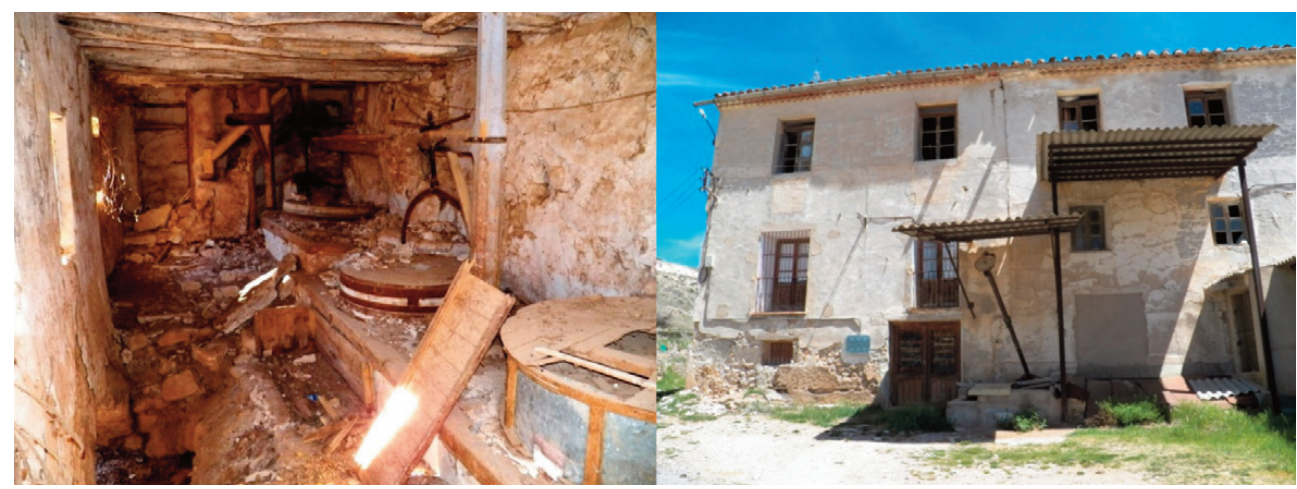

Figura 5. Sala de molienda del Molino Nuevo de Orrios.

Figura 6. Fábrica de harinas de Barrachina.

\subsubsection{Fábricas, batanes y producción eléctrica}

Las fábricas y batanes identificados guardan también, en cuanto a su emplazamiento, una estrecha vinculación con el aprovechamiento hidráulico. Aproximadamente el 93\% de estos elementos se sitúa a menos de 500 metros de los ríos principales, de los cuales detraían el agua necesaria para el funcionamiento de la maquinaria y, tal y como se ha comentado arriba, para otros menesteres relacionados con la actividad respectiva (lavado de paños o lana, elaboración de papel, etc.). La fabricación de lanas tiene una historia que se remonta, en Teruel, a por lo menos la Edad Media. Los principales territorios productores eran las sierras de Gúdar, el Maestrazgo de Teruel, y la Sierra de Albarracín, donde según De Asso (1795), a finales del siglo XVIII se producían "las lanas más finas del reyno de Aragón” (De Asso, 1795: 184). A comienzos de la revolución industrial, Teruel era un territorio con una enorme producción textil, con más 
de 4000 pelaires o maestros tejedores en toda la provincia en 1796, con importantes núcleos como Rubielos de Mora con 997 pelaires, Villarroya de Los Pinares con 157 u Olba con más de 230 telares (Peiró, 2000: 107).

Por ello, comarcas como Gúdar-Javalambre, Maestrazgo y La Matarranya (ver tabla 1) reúnen el $70 \%$ de los emplazamientos de fábricas y batanes, siendo evidente la concentración de fábricas textiles en las dos primeras y de papel y sulfuro en La Matarranya. Esta concentración fabril se debe tanto a la presencia de cursos fluviales, antes señalada, como a la permanencia a lo largo del tiempo de importantes cabañas ganaderas como las de las sierras de Gúdar o de Albarracín. Como conjunto fabril destacan sobre todo los de la cuenca del río Mora y del Matarranya, donde se concentran las fábricas textiles y de papel más importantes. Algunos de estos conjuntos conformaron auténticas colonias industriales, de un tamaño comparable incluso a las colonias catalanas junto al Llobregat. Es el caso de las fábricas de papel de Villarluengo o de Beceite (Lozano, 1999), o dentro del sector textil, las tres fábricas de lanas de Los Capotes en Nogueruelas.

Habría que mencionar también el importante papel desempeñado por las fábricas de harinas, que suponen el paso a la producción industrial de este producto en la provincia. Aún en 1963 se contabilizaban 25 grandes fábricas de harinas en Teruel, que fabricaron en ese año nada menos que 173.000 quintales métricos, siendo la más destacada de la provincia la de Yago y Pascual de la provincia (AHPT, 2017).

Por otro lado, las instalaciones para la producción eléctrica están constituidas principalmente por fábricas de luz y centrales hidroeléctricas, siendo lógicamente remarcable su vinculación espacial con los cursos de agua, ya que ninguna dista más de 250 metros de ellos (Figura 12). Se trata de pequeños centros de generación y en general están bastante separados entre sí. En algún caso estas pequeñas centrales eran clave para el suministro eléctrico de algunas poblaciones y centros fabriles. De ahí su elección por agrupaciones de maquis como objetivo prioritario de sabotaje durante la posguerra. Gúdar-Javalambre, Maestrazgo y Andorra-Sierra de Arcos son las comarcas en las que con mayor frecuencia aparece esta tipología de pequeña central. Mención aparte merecen las grandes centrales térmicas de Andorra, Aliaga o Escucha, en este caso dependientes no tanto de un curso fluvial, sino de las minas de lignito (carbón) que les proporcionaban el combustible necesario para las turbinas.

Al igual que los molinos, las fábricas, batanes y elementos para la producción eléctrica han tenido por su cercanía a los ríos una doble afección: un notable atractivo debido a su entorno paisajístico y biogeográfico y un riesgo mayor de deterioro por su exposición a avenidas o a la invasión por la vegetación. 


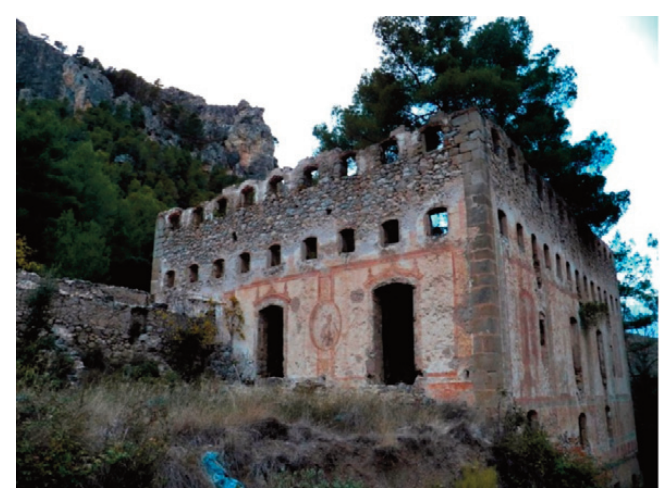

Figura 7. Fábrica La Bonica en Beceite.

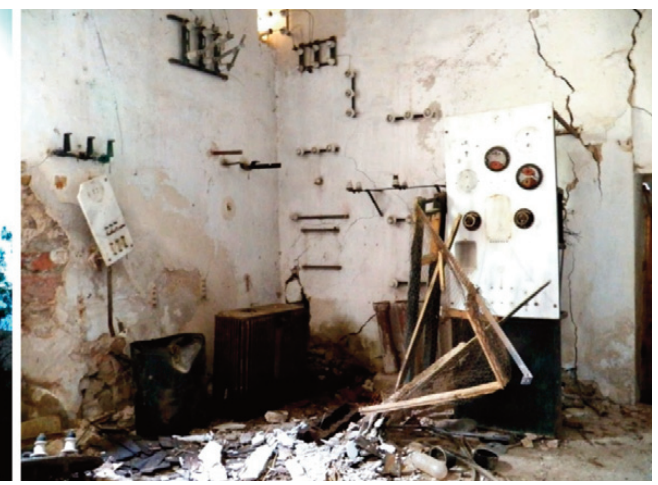

Figura 8. Molino de abajo y Fábrica de luz en Torres de Albarracín.

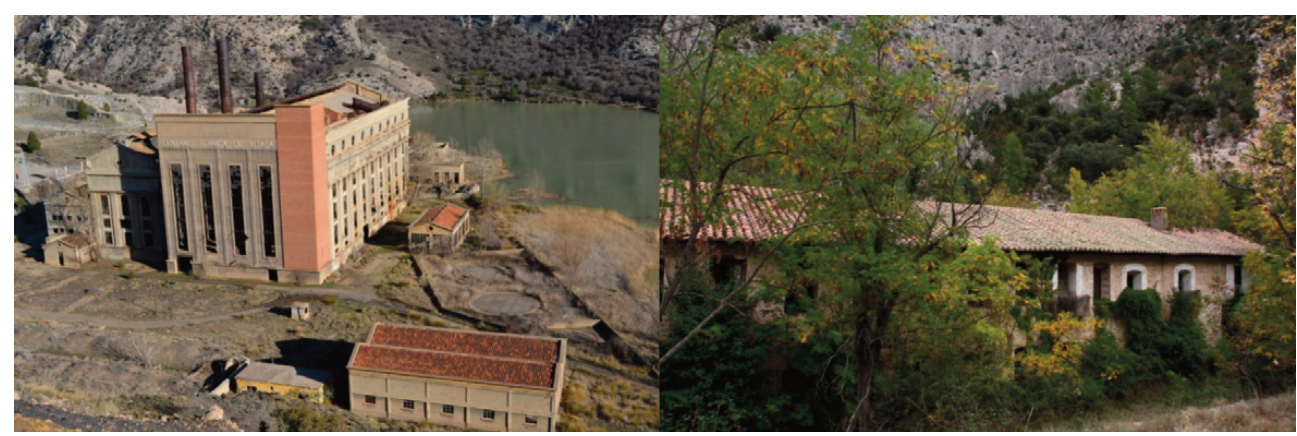

Figura 9. Central térmica de Aliaga.

Figura 10. Fábrica textil de Villarluengo. 

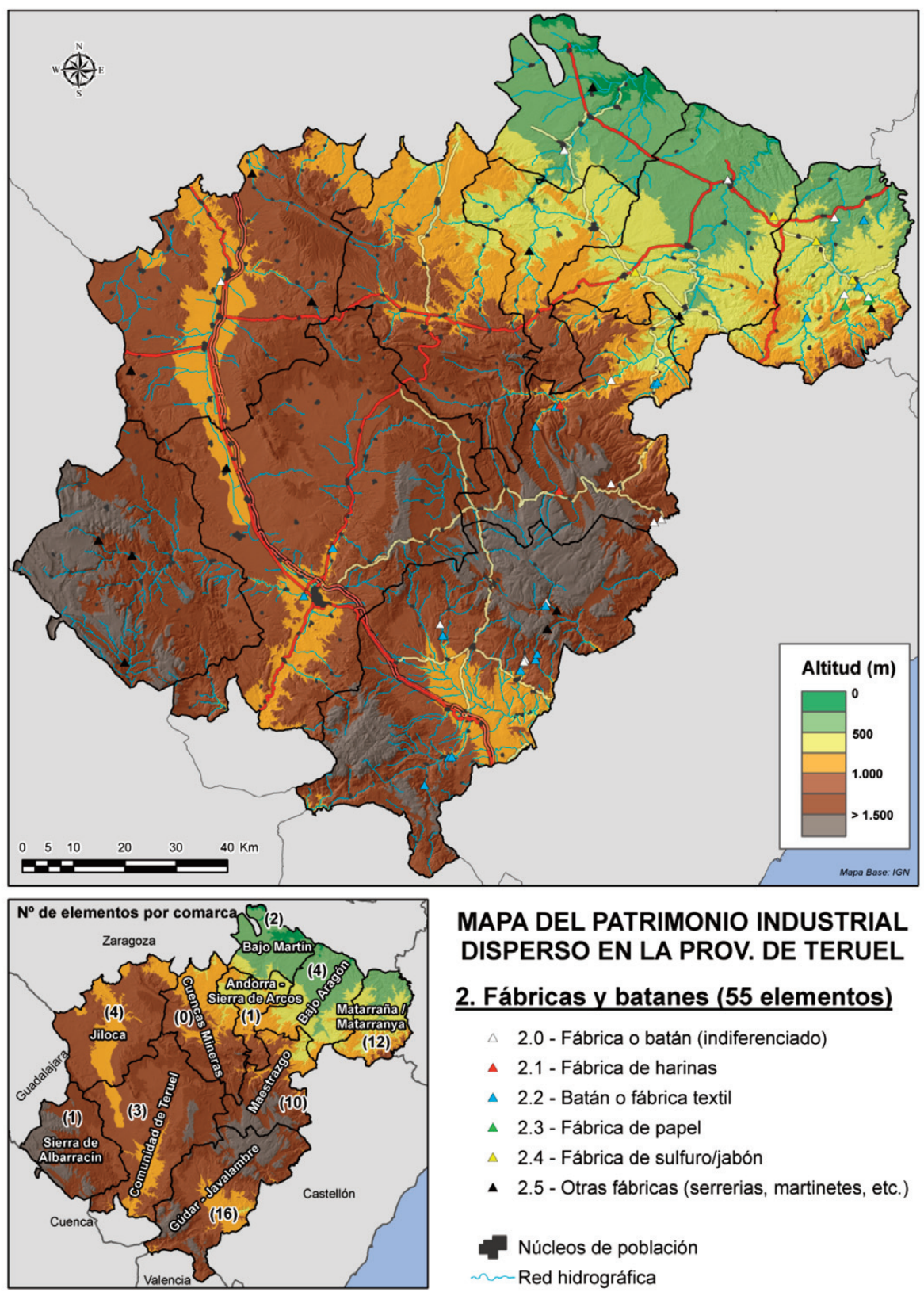

MAPA DEL PATRIMONIO INDUSTRIAL DISPERSO EN LA PROV. DE TERUEL

\section{Fábricas y batanes (55 elementos)}

$\triangle 2.0$ - Fábrica o batán (indiferenciado)

- 2.1 - Fábrica de harinas

A 2.2 - Batán o fábrica textil

42.3 - Fábrica de papel

$\triangle 2.4$ - Fábrica de sulfuro/jabón

- 2.5 - Otras fábricas (serrerias, martinetes, etc.)

Núcleos de población

Red hidrográfica

Figura 11. Mapa de fábricas y batanes.

Fuente: Elaboración propia. 

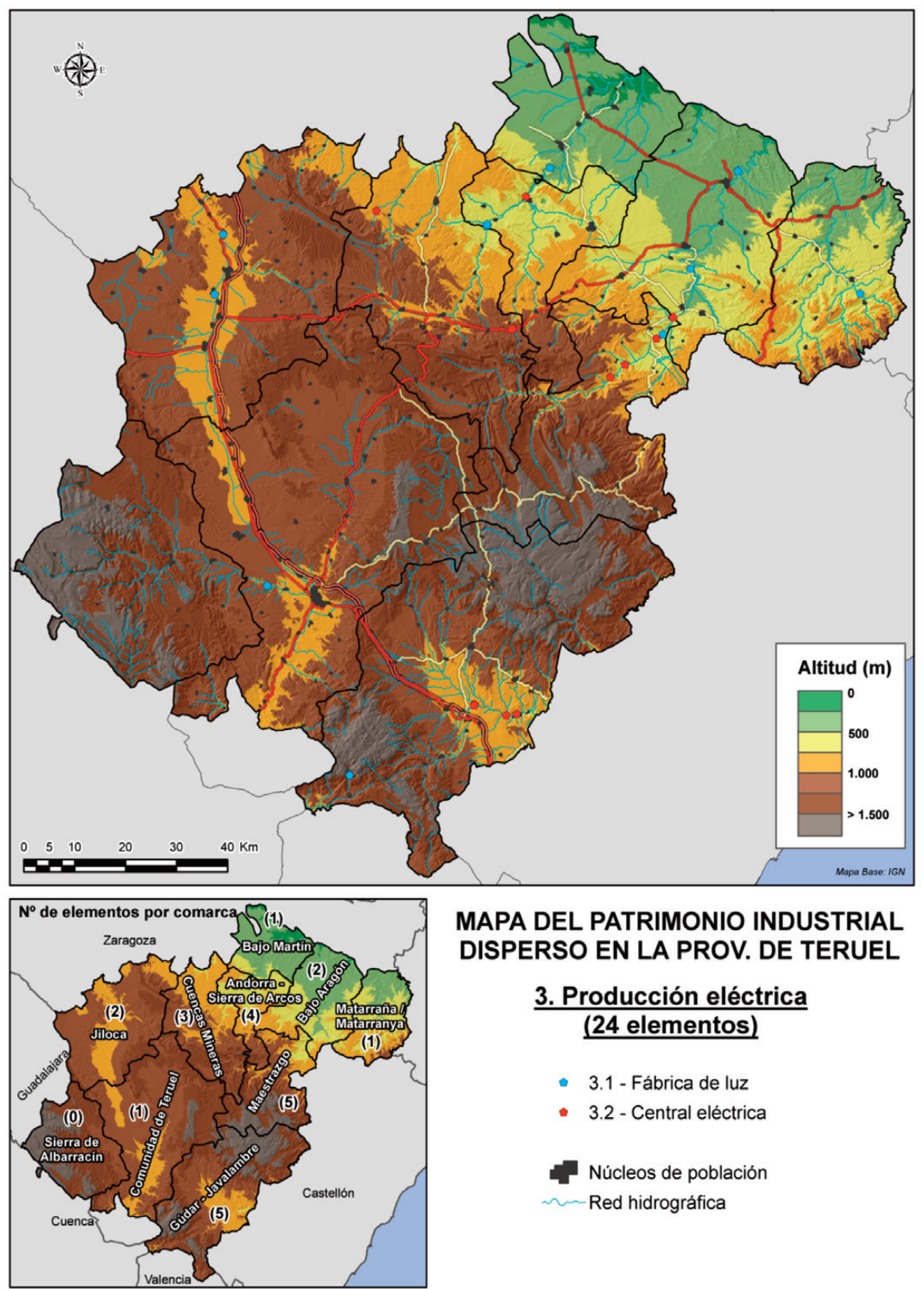

MAPA DEL PATRIMONIO INDUSTRIAL DISPERSO EN LA PROV. DE TERUEL

3. Producción eléctrica (24 elementos)

- 3.1 - Fábrica de luz

- 3.2 - Central eléctrica

Núcleos de población

Red hidrográfica

Figura 12. Mapa de instalaciones de producción eléctrica. Fuente: Elaboración propia. 


\subsubsection{Extracción y transformación minera y otros elementos}

En esta categoría queda roto el vínculo espacial a la red hidrográfica principal y pasa a ser la proximidad a los recursos minerales la que prevalece en la decisión de localización. Así, casi el 70\% de las minas, hornos, almacenes, etc. que integran esta categoría se ubica a más de medio kilómetro de los cursos fluviales. En contraposición, la altitud media a la que se emplazan las instalaciones de extracción y de transformación minera (Figura 13) es la más alta de las cinco categorías analizadas, con cerca del 70\% de los elementos a más de 1.000 m s.n.m. La cercanía a las vetas de mineral, localizadas en las sierras del Sistema Ibérico, explica esa altitud media relativamente elevada. Por comarcas, Cuencas Mineras se sitúa a la cabeza por número de instalaciones mineras, concentrándose entre dicha comarca y las de Comunidad de Teruel, Jiloca y Andorra-Sierra de Arcos casi las tres cuartas partes de elementos de esta categoría.

De nuevo, la historia de la minería en esta provincia ha sido escasamente estudiada, pese a la variedad de minerales explotados, como de tipos y empresas explotadoras a lo largo de la historia. Existen numerosos vestigios de minería artesanal, como en La Zoma o Linares de Mora, hasta auténticos complejos industriales como el de Sierra Menera en la comarca del Jiloca, SAMCA en Ariño y Andorra, o MFU en Utrillas (Sanz, 2008). Solo en el término de Escucha llegó a haber abiertos a mediados del siglo XX casi medio centenar de pozos mineros de carbón, lo que da cuenta de la importancia del sector en estos territorios (Fabro, 2007).

Por último, el conjunto genérico de otros elementos de patrimonio industrial disperso de la provincia de Teruel, que reúne martinetes, serrerías, peguerías, etc. no muestra un patrón espacial demasiado definido salvo, de nuevo, por su cercanía a la red hidrográfica, ya que más de la mitad de ellos se localiza a menos de $500 \mathrm{~m}$ de los principales cursos. Por comarcas es remarcable la frecuencia de estos elementos en la comarca de Gúdar-Javalambre, que concentra el 31\% del total provincial. Aunque aparecen con cierta profusión en la cartografía histórica de primera mitad del siglo XX, no se han conservado demasiado bien por lo general fuera de los núcleos urbanos, siendo habitual verlos reconvertidos a viviendas o, en el caso de las peguerías, prácticamente sin vestigios físicos. 

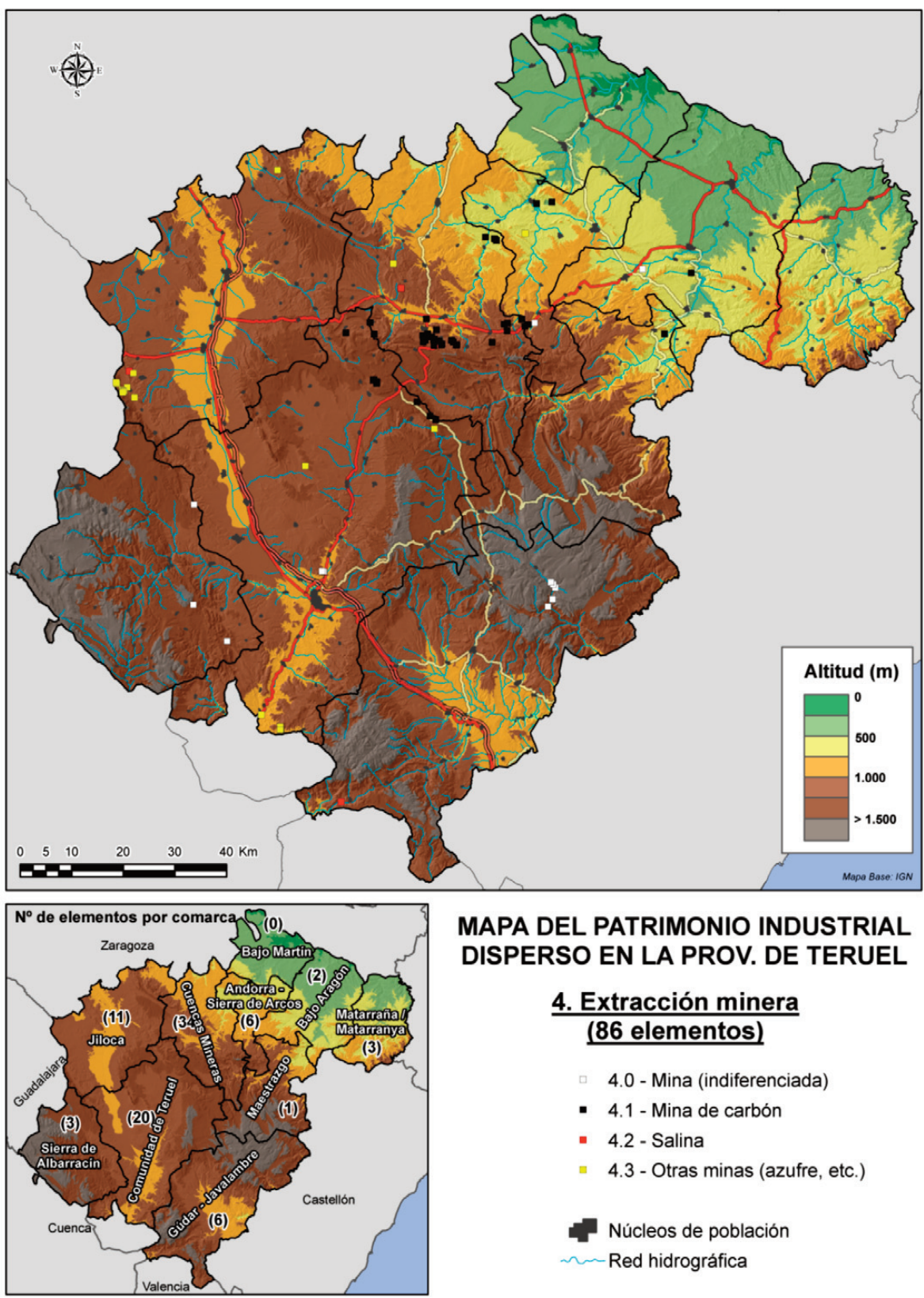

MAPA DEL PATRIMONIO INDUSTRIAL
DISPERSO EN LA PROV. DE TERUEL

\section{Extracción minera (86 elementos)}

4.0 - Mina (indiferenciada)

- 4.1 - Mina de carbón

- 4.2 - Salina

- 4.3 - Otras minas (azufre, etc.)

Núcleos de población

Red hidrográfica

Figura 13. Mapa de instalaciones de extracción y transformación minera. Fuente: Elaboración propia. 

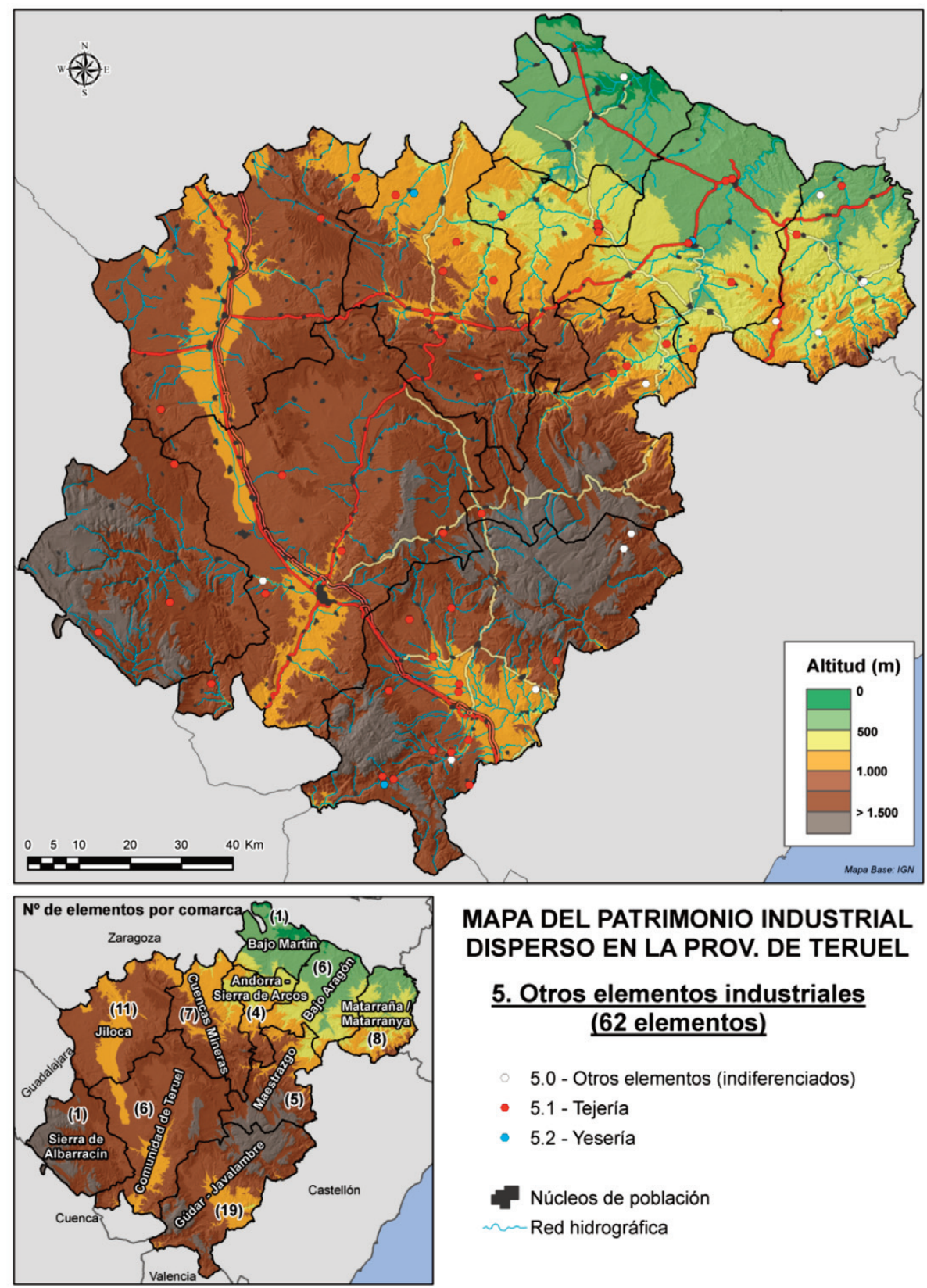

MAPA DEL PATRIMONIO INDUSTRIAL DISPERSO EN LA PROV. DE TERUEL

\section{Otros elementos industriales (62 elementos)}

5.0 - Otros elementos (indiferenciados)

- 5.1 - Tejería

- 5.2 - Yesería

Núcleos de población

Red hidrográfica

Figura 14. Mapa de otros elementos de industria dispersa.

Fuente: Elaboración propia. 


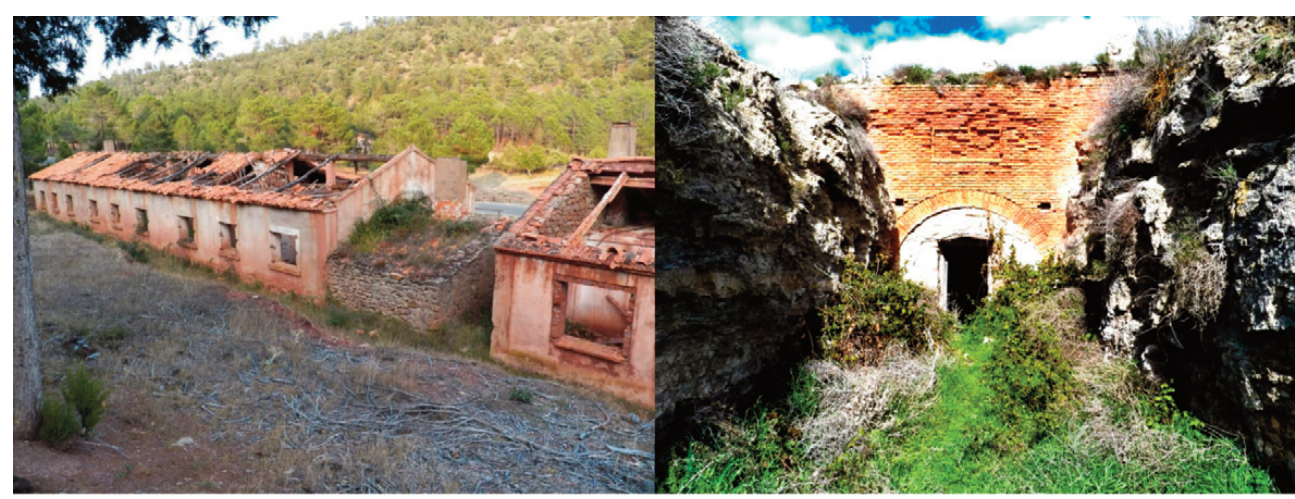

Figura 15. Casas de resineros en Albarracín.

Figura 16. Minas de Libros.

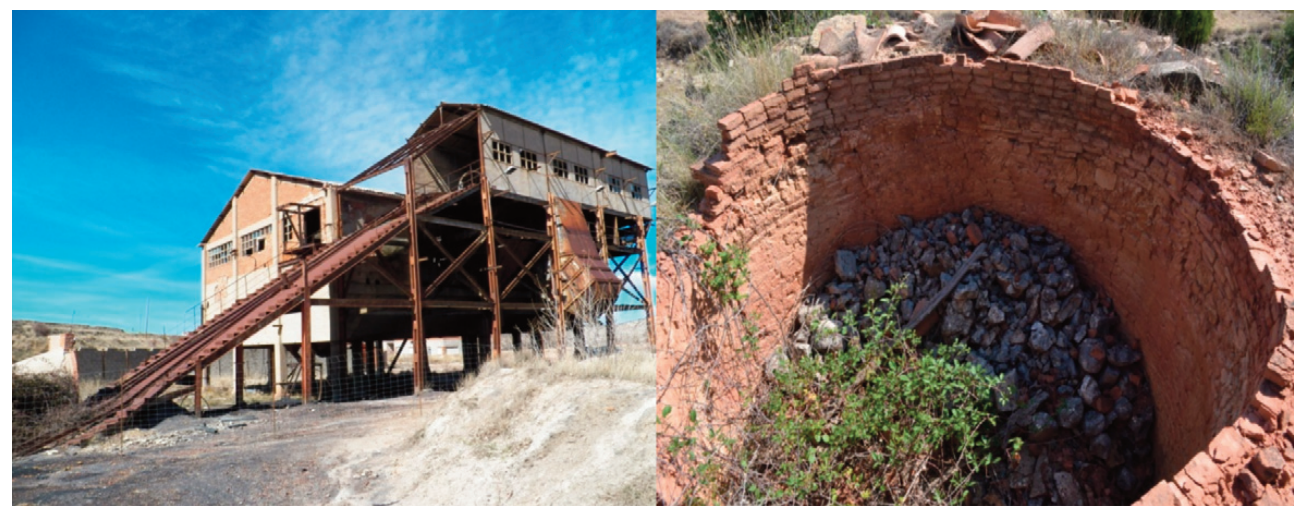

Figura 17. Pozo Lancis en Escucha.

Figura 18. Antiguo horno de tejas en la fábrica Las Golondrinas en Cabra de Mora.

\subsection{Análisis histórico. Cuando Teruel era el Manchester de Aragón}

Paralelamente al inventario y evaluación de los restos físicos "arqueológicos" producidos por el abandono sucesivo de aquellas actividades, se ha indagado a través de entrevistas, documentos de archivo, bibliografía etc. en la propia actividad. A continuación se presenta una aproximación a la actividad industrial turolense que vivifica los sobrios datos del inventario.

\subsubsection{Tres ciclos industriales efímeros}

"El trabajo del minero era muy duro y las mujeres nos hacíamos cargo de la familia, lo pasábamos muy mal porque se sufría mucho porque sabiamos que habia mucho peligro en la mina. Nosotras nos encargábamos de criar a los bijos y cuando 
habia un accidente en la mina éramos las primeras en acudir por si podiamos ayudar en cualquier cosa. En mi caso mi padre se quemó en la mina después de una explosión y tuvimos que cuidarlo más de tres meses con las quemaduras que sufrió. Finalmente murió. Y mi marido también sufrió un accidente por desprendimiento en la mina, nos tuvimos que trasladar a Sagunto para los cuidados, dejando en el pueblo a mis hijos. Tampoco logró sobrevivir y finalmente murió".

Delia Cortada, Esposa e hija de mineros de Escucha, [Entrevista].

Teruel es hoy en día la segunda provincia menos poblada de España, solo superada por Soria, y una de las más envejecidas. En muchos de sus municipios, el futuro inmediato es más que incierto y de hecho, durante gran parte del año y especialmente en los largos días de invierno, apenas son pocas decenas las personas que habitan en ellos. Con frecuencia se habla de la crisis de las actividades agrarias, la dureza de su clima y la escasez de infraestructuras y servicios, como las causas generales que explican que este territorio rodeado de grandes ciudades como Valencia, Zaragoza, Castellón o Tarragona, sea un auténtico desierto demográfico. No obstante conviene matizar que la sociedad turolense no solamente ha dependido históricamente de la agricultura y ganadería. En su historia reciente y no tan reciente jugó un papel fundamental el desarrollo fallido de varias actividades industriales esenciales como la extracción de carbón o la fabricación textil, papel o electricidad, que acompañaron las diferentes revoluciones industriales que España vivió a lo largo de los siglos XIX y XX, con cierto retraso respecto a sus vecinos europeos, en cuya decadencia hay que situar también otra de las causas principales de la despoblación de este territorio (Peiró, 2000). Sin embargo, a diferencia de otros territorios cercanos como Vizcaya, Asturias o Catalunya, estas actividades no vinieron para quedarse, sino que formaron parte casi siempre de ciclos temporales, que sin embargo transformaron profundamente la naturaleza, sociedad y economía de numerosas comunidades, para el beneficio casi exclusivo de unas élites, empresas e intereses ajenos y lejanos a los de la provincia. En efecto, además de pueblos, pastos y campos abandonados, Teruel también destaca por un ingente y en parte desconocido patrimonio industrial compuesto por casi medio millar de elementos de patrimonio como se ha visto, hoy por desgracia poco estudiado, y menos valorado, como se ha apuntado en la introducción.

Un componente esencial de esta industrialización fallida es la explotación minera e industrial moderna en forma de colonias y pequeñas fábricas y bajo el mando de empresas familiares. Las nuevas ruralidades creadas con la minería industrial y las fábricas de harinas, textiles o de papel, según se observa en el testimonio de Delia Cortada, viuda e hija de mineros muertos en su trabajo en las minas de Escucha (Teruel), supuso pocas mejoras en la calidad y esperanza de vida de las gentes del campo. Desde finales del siglo XIX se vivió el apogeo de la colonización interna con sucesivos ciclos mineros e industriales implantados en el medio rural. A diferencia de la evolución vivida por las actividades tradicionales como el pastoreo, la agricultura de secano o la artesanía, que desde 
comienzos del siglo XIX ya comienzan a experimentar un declive bastante paulatino, sutil y con muchos vaivenes históricos, la llegada de las revoluciones industriales a numerosos territorios rurales de Teruel, fueron procesos bruscos, súbitos y casi siempre temporales. Diversos ciclos tecnológicos fueron sucediéndose en cuestión de décadas, ciclos que demandaban gran cantidad de materias primas como carbón, hierro, azufre, plomo, cobre u oro, y posteriormente petróleo y gas natural, así como de mano de obra. Por esta razón, la llegada de la industria al medio rural constituye el mejor ejemplo de colonización interna del territorio, con la creación de nuevos asentamientos o colonias en prácticamente todo el mundo desde el siglo XIX, únicamente con el propósito de extraer algún recurso natural o producir alguna manufactura, ocasionando fracturas sociales irreparables en numerosas comunidades rurales e impactos ambientales irreversibles. Collantes destaca como ciclos tecnológicos los ciclos manufactureros y los ciclos mineros (Collantes, 2004, p. 150), a los que se podría añadir los agrícolas-industriales:

- Ciclos agrícolas-industriales: En el caso de Teruel se refiere al proceso de modernización de la antigua molinería hidráulica para la fabricación de harina, y en algunas comarcas de aceite.

- Ciclos manufactureros modernos: Son especialmente relevantes las fábricas textiles, de papel y la producción eléctrica.

- Ciclos mineros: Aprovechamientos mineros y complejos industriales de extracción de carbón y otros minerales.

La principal distinción entre éstos ciclos y otros anteriores es que básicamente nacen al calor de las revoluciones industriales y dentro de una lógica puramente capitalista. Además, en la forma común de explotar el recurso natural o fuente de energía deseado, sea agua, electricidad, tierra o minerales, que como se ha apuntado se hace en muchos casos a partir de la instalación de colonias industriales, mineras, y agrícolas en territorios rurales alejados de los núcleos de población y que nada tienen que ver con el territorio en el que se asientan. A partir de estos ciclos se crean nuevas ruralidades, muchas de las cuales conforman territorios nuevos hasta la actualidad, pero en muchos otros casos se trata de ruralidades efímeras.

El proyecto colonizador del Estado burgués capitalista no se agota solamente con la expansión del modelo de colonia industrial o agraria o en la construcción de grandes infraestructuras hidráulicas para la ciudad a lo largo y ancho de la provincia de Teruel. A lo largo del siglo XX se estructura en España un capitalismo concentrado, monopolizado y oligarquizado desde Madrid y Barcelona básicamente, dejando vastas regiones de Aragón con un poder económico muy reducido y, en consecuencia, con un nulo poder político de manera que: "solo han entrado en juego en el sistema de una forma dependiente y subordinada para reforzar la incontenible ascensión de los centros capitalistas del mercado español a través de toda una serie de mecanismos que se vienen catalogando como "coloniales" (Muñoz, 1978, p. 29). No obstante, son las áreas rurales las que disponen de los recursos naturales necesarios para alimentar las sucesivas revoluciones industriales. 
De hecho, numerosas áreas montañosas de Teruel ya habían experimentado durante la Edad Moderna un dinamismo manufacturero, agrícola y minero basado en la energía hidráulica, la creciente demanda de materias primas y la implantación de fábricas, algunas formaron auténticas colonias textiles como las fábricas de los Igual en Nogueruelas o las de Villarluengo. Este dinamismo fue el motor de creación de nuevas ruralidades a lo largo de toda la historia moderna. Sin embargo, las nuevas técnicas de extracción y fabricación posibilitadas por la revolución industrial (como la máquina de vapor y el transporte por ferrocarril) y la extensión del carbón mineral como principal fuente de energía, creó un boom en la minería de este mineral, permitió la colonización agrícola de nuevas tierras gracias a la incipiente mecanización de las faenas agrícolas, y favoreció la conversión de la antigua industria molinera que poblaba numerosos ríos, en los primeros centros industriales modernos de muchas áreas rurales, cambiando así profundamente el paisaje rural. A continuación se hace un breve repaso de las tres principales actividades industriales de la provincia y de su devenir histórico: la molinería y fabricación de harinas, la minería, y por último la industrial textil en fábricas o en colonias.

\subsubsection{La molinería y fabricación de harinas}

Tal y como se ha observado en el apartado anterior, la molinería de harinas constituye el sector protoindustrial más sobresaliente de la provincia, que unido al de la fabricación de harinas supuso durante muchos años el motor no solo económico, sino de subsistencia de numerosas poblaciones.

La historia reciente de la molinería se podría dividir en tres subperiodos diferenciados: hasta la Guerra Civil, época de la dictadura franquista, y a partir de los años 70. Durante la primera etapa, desde finales del siglo XIX hasta la Guerra Civil, la mayor parte de molinos harineros de la provincia están plenamente activos y durante las primeras décadas del siglo XX se construyen una buena parte de los inventariados en este trabajo. El oficio de molinero es duro, pero al mismo tiempo lucrativo y esencial para todas las comunidades rurales, que tienen en el cereal su base de alimentación tanto de las personas como de los animales de tiro y labor. Este primer subperiodo se distingue también por el inicio de la tecnificación de algunos molinos, básicamente por la instalación de turbinas, que permite, además de la molienda, la producción de energía eléctrica y consecuentemente la electrificación del medio rural. Algunos ejemplos interesantes son el molino del Tormagal que proporcionaba luz al monasterio del Olivar en Estercuel (Carbonell, 2016), o la fábrica de luz de la empresa "Virgen de la Peña" en Pitarque que se dedica por completo a este fin.

Un segundo subperiodo arranca con la Guerra Civil y marca el inicio del declive de la molinería hidráulica. A la destrucción causada por la Guerra Civil hay que añadir los años de la posguerra, en el que los molinos se convierten en objetivo militar por la gue- 
rrilla del maquis, y en objeto de control severo tras la instauración de las cartillas de racionamiento y la creación del Servicio Nacional del Trigo, por parte del nuevo gobierno de Franco. Se viven años de inseguridad y numerosos molinos son asaltados o saboteados por la guerrilla del maquis, o precintados y cerrados por la Guardia Civil por considerarse colaboracionistas del maquis, o bien centros de estraperlo y molienda ilegal.

"De La Hoz tenía que llevar el cupo a la harinera Valenciana de la estación de Mora. Echaba $300 \mathrm{~kg}$ al burro y tardaba 2 horas y media en llegar. Luego de descargar y firmar papeles, me tocaba regresar por el mismo camino y mientras mi mujer se quedaba en la Hoz con la molienda. El molino nunca se podía quedar vacio para evitar robos y asaltos".

Ángel Pinazo, molinero de Villaspesa y de La Hoz (San Agustín), [Entrevista].

A este contexto político conflictivo, hay que añadir la consolidación de la industrialización del sector con la construcción de varias fábricas de harinas, que comienzan a funcionar con turbinas, y tienen una capacidad de producción muy superior a la de los molinos, a los que muchas veces sustituyen físicamente en el mismo emplazamiento. Con la generalización del transporte en carretera a partir de los años 60 y la conformación de un mercado nacional del trigo, muchos pequeños molinos se ven obligados a cerrar por su menor productividad. Esta crisis se generaliza a partir de la década siguiente, que supone el final de la producción molinera.

El tercer y último periodo de la molinería de harinas se inicia con la crisis del petróleo de los años 70 y la posterior reestructuración industrial que se impuso en España en la década siguiente, con la integración europea. Definitivamente llega el fin de la industria molinera en Teruel. Ello es una causa más de la expulsión de miles de personas en muy pocos años de pueblos que literalmente vivían del sector agropecuario, incluyendo la industria agroalimentaria artesanal. En este sector, la creciente concentración de fábricas harineras en las ciudades, cada vez más tecnificadas y con mayor capacidad de producción, obligan a cerrar cientos de molinos y pequeñas harineras. El desarrollo capitalista del sector impone nuevos patrones de localización de las fábricas de harinas, a partir de esta época en grandes complejos industriales junto a ciudades y vías de comunicación rápidas. La mayor parte de la producción de harinas se traslada a otras provincias, dejando en las décadas siguientes a Teruel casi sin fábricas de este tipo. Hasta las fábricas de mayor capacidad, como la de Santa Eulalia o la de Alfambra, terminan echando el cierre. Al contrario que con otros sectores o territorios, aquí nunca llegaron ayudas o planes para la reconversión, modernización o nacionalización del sector. En pocos años, decenas de molineros, empacadores de grano, almacenistas, oficinistas o mecánicos perdieron su empleo, trasladada gran parte de la fabricación de harinas a otras provincias. 


\subsubsection{La minería en Teruel}

Cada ciclo tecnológico tiene sus especificidades, tanto por sus técnicas de extracción y procesamiento como por sus impactos ambientales o el tipo de organización empresarial que actúa como inversor, pero sin duda fueron los ciclos mineros la clave para la expansión del capitalismo. Las particularidades de la actividad minera hace que se distinga de otras como las agrícolas o las netamente industriales.

En primer lugar, los ciclos mineros tienen normalmente una duración de pocas décadas en la mayor parte de los casos, generan una gran actividad y una inmensa demanda de mano de obra en muy poco tiempo. En Teruel el ejemplo más claro en este sentido lo constituyen dos grandes compañías mineras: MFU de Utrillas y Sierra Menera en Ojos Negros (Biel y Hernández, 2008). En segundo lugar, han sido una de las principales vías de proletarización de la población campesina. El relato más extendido en el origen de muchas colonias y poblaciones mineras es el de la llegada de familias de diferentes áreas rurales atraídas por los salarios supuestamente altos y fijos del oficio de minero, frente a la inseguridad de la vida campesina ligada a la suerte de la cosecha. La apertura de un complejo minero entraña un trauma silencioso entre dos comunidades: los habitantes preexistentes, normalmente vinculados a la agricultura y ganadería, y los "colonos" o trabajadores de la mina, que llegan en masa en muy pocos años a territorios en los que normalmente las densidades demográficas son bajas. Rosa López Bielsa, guía del museo minero de Andorra, MWINAS, habla en primera persona sobre este conflicto:

"Vino ENDESA e bizo un poblado para los mineros. No teníamos casi relación con los inmigrantes que vinieron sobre todo de Andalucía, a trabajar en la mina. Era un barrio moderno con economato, instalaciones deportivas y centro médico, todo de mejor calidad que lo que habia en el pueblo, pero relación había poca".

[Entrevista].

En efecto, como afirma Alquézar (2008), las empresas mineras tuvieron una política de servicios sociales generosa, construyendo viviendas ya en los años 40 y 50 con luz y agua corriente cuando casi nadie en la provincia disponía de estos servicios, además de economatos, escuelas y atención sanitaria. Paradójicamente, la mayoría de estos colonos no son sino habitantes de otras ruralidades que a través de la minería son proletarizados. La minería representa en muchos casos el encuentro entre dos ruralidades que durante muchos años se ignoran mutuamente.

En tercer lugar, como relataba Delia Cortada, la vida del minero no es nada fácil y poco tiene que ver con la del obrero textil o agrícola. Por un lado se trata de uno de los trabajos más duros y peligrosos que existen, especialmente por las condiciones de trabajo casi sin seguridad y de largas horas en galerías muchas veces expuestos a gases tóxicos y polvo. Por otro lado, el minero no deja de ser un simple engranaje en la gran empresa minera que capitaliza la actividad, y en este sentido no tiene voz ni voto 
en sus decisiones ni por lo tanto estabilidad laboral. En el momento en el que la extracción del mineral deja de ser rentable, la colonia cierra su actividad y en muy pocos años es abandonada, aunque esta haya atraído a miles de familias, como ocurrió con el cierre de grandes complejos mineros como el de Sierra Menera en Ojos Negros, SAMCA en Ariño y Andorra o MFU en Utrillas (Alquézar, 2008).

En cuarto lugar, el territorio explotado por una compañía minera suele ser bastante extenso y es modificado profundamente a lo largo del periodo de actividad, especialmente en la minería a cielo abierto, dejando un legado de contaminación que dificulta extraordinariamente su reconversión posterior hacia otras actividades. Además, la explotación minera suele ir acompañada de toda una serie de infraestructuras auxiliares como ferrocarriles mineros, lavaderos de mineral o plantas de procesamiento que a su vez requieren de mucho espacio y que contribuyen en gran medida a crear un territorio completamente distinto al preexistente. En este sentido la actividad acaba generando un proceso doble de desarticulación social en las áreas rurales en las que se asienta: con la llegada y rápida expansión crea un paisaje industrial que altera completa y físicamente el territorio: pozos mineros, nuevas colonias, estaciones de ferrocarril, escombreras, piscinas de lavado surgen en muy poco tiempo. El cierre definitivo de una mina es un segundo momento de desarticulación: la sociedad totalmente genuina creada al calor de este recurso, deja de tener sentido también súbitamente. Quizás han pasado siglos desde que ese territorio fuese una aldea y es casi imposible volver a desarrollar las actividades preexistentes: o no quedan campesinos, o éstos han sido completamente asimilados a la actividad minera, que a lo largo de la historia ha generado toda una cultura a su alrededor. Por la dureza de su trabajo se genera una conciencia de clase y una identidad muy diferenciada que es clave para entender la historia del movimiento obrero y de territorios como la sierra de Arcos y las Cuencas Mineras de Teruel. Pero al mismo tiempo la posibilidad de continuar con cualquier actividad industrial o minera es extremadamente complicada, por lo menos dentro de las lógicas capitalistas del beneficio económico como única meta.

\subsubsection{Las fábricas textiles y las colonias industriales y mineras}

No es, sin embargo, la minería el único ejemplo de colonización industrial. Contemporáneamente a las primeras colonias mineras industriales surge como ciclo industrializador importante la manufactura textil moderna en áreas rurales. El caso más evidente es el de la transformación en numerosos ríos de la provincia, de antiguos batanes y molinos, en modernas fábricas textiles de lavado, cardado, hilado y producción final sobre todo de fajas y mantas. Esta transformación siguió un modelo completamente innovador de producción y de sociedad: las colonias industriales. La ley de Colonias Agrícolas de 21 de noviembre de 1855 fue el catalizador de las industrias textiles para emprender la creación de colonias industriales y agrícolas en España (Godoy, 2014). 
Con el modelo de colonia industrial, numerosos territorios rurales comienzan a mutar de manera espectacular. El propio término de colonia deja claro que se trata de un modelo de poblamiento y organización totalmente exógeno al territorio en el que se instala. Es un concepto de asentamiento originario de Inglaterra, cuna de la industrialización desde el siglo XVIII. Una colonia industrial o minera es la suma de la fábrica y las viviendas de todos aquellos que trabajaban en ellas, desde el director hasta el último aprendiz. En ella se podía encontrar la iglesia, el economato, las escuelas, lavaderos, enfermerías, locales sociales, teatros, oficinas bancarias, etc. así como la residencia de los propietarios, que acudían en los periodos vacacionales, residiendo alguno de ellos en la misma para mejor control de la producción o extracción del mineral (Godoy, 2014). Sin duda, en el caso de Teruel uno de los mejores ejemplos es la colonia de Las Fábricas de Villarluengo, que llegó a contar con un asentamiento permanente en un núcleo en el que llegaron a residir 153 personas, contaba con escuelas, iglesia, taberna, molino y varios comercios (Salillas, 2008, p. 77). Dentro del sector minero, destaca sin duda el enorme complejo urbano construido en Ojos Negros con diversos barrios residenciales y un barrio central conocido popularmente como el barrio de Sierra Menera o "la ciudad del dólar", pues contaba con casino, cine, economato, hospital y hasta piscina (AASM, 2009, p. 12). En síntesis, se trata de la implantación de pequeñas sociedades urbanas capitalistas en el medio rural, formada mayoritariamente por trabajadores de origen rural, que pasan en muchos casos de ser campesinos a obreros industriales. La principal razón para la ubicación en el medio rural es para el caso de la industria textil y como se ha analizado anteriormente, la búsqueda de cursos de agua con suficiente cantidad y desnivel como para movilizar toda la maquinaria necesaria para la producción, recursos que solamente se podía dar en los cursos fluviales de montaña como en el caso del Maestrazgo o Gúdar. En el caso de las colonias mineras se explica por la necesidad de situarse junto al yacimiento del mineral, ya que hasta fechas muy recientes la actividad minera, la simple extracción de materias primas, requería de una enorme cantidad de mano de obra que debía residir lo más cerca posible del pozo minero. Sin embargo, también cabe destacar la función de pacificación social que ejercía la colonia, algo visible incluso en su arquitectura, muchas veces concebida con el fin de controlar a los obreros.

Realmente se trata de colonias en todos los sentidos de la palabra, con un tipo de sociedad y modelo de vida totalmente jerárquico y controlado casi completamente por los gerentes o representantes de la empresa con un trato paternalista en el mejor de los casos, hacia sus empleados. Este caso es observable en los barrios mineros de Aliaga, como el de Santa Bárbara, donde la casa de ingenieros y de la gerencia se ubica junto a la iglesia y en una posición más elevada respecto a las viviendas de obreros, al igual que en el vecino barrio de La Aldehuela construido para los trabajadores de la central térmica de Aliaga. En definitiva, se trata de un modelo radicalmente distinto al de las sociedades rurales tradicionales del territorio en el que se asentaba. Las colonias compartían un mismo esquema urbanístico: un espacio productivo, donde están las fábricas y las infraestructuras necesarias para la actividad extractiva o industrial; y otro doméstico, (que forman 
el núcleo y la esencia de la colonia obrera) donde los trabajadores viven y cuentan con todos los servicios, como escuela, café, teatro, economato, dispensario médico, etc. Y en el punto más alto, la torre del amo o casa del ingeniero o gerente, donde el propietario residía durante sus visitas semanales o en verano (Godoy, 2014).

La fórmula proporcionaba una excelente rentabilidad al propietario capitalista, ya que al ser una sociedad bastante cerrada, el absentismo era casi nulo y los gastos cotidianos de los trabajadores, en la cantina, la barbería, el estanco o el alquiler del piso revertían en los propios negocios de la colonia. Un ejemplo es el de las minas de Libros, situadas a más de siete kilómetros de la cabecera municipal, con lo que todos los servicios básicos, así como el comercio, estaban en la propia colonia, que contaba con escuelas, economato, comercios y bares. Si las sociedades rurales y masoveras turolenses estaban basadas en la cooperación y el trabajo en comunidad sin grandes jerarquías, las nuevas sociedades coloniales son un fiel reflejo de un microcosmos de las nuevas sociedades capitalistas industriales que comienzan a desarrollarse con un esquema fuertemente jerárquico a partir de la segunda mitad del siglo XIX.

Las colonias industriales supusieron un cambio radical en los modelos de vida de muchas comunidades rurales, que pasaron de ser pequeños agricultores, artesanos o ganaderos con diferentes faenas según la estación, a asalariados fijos en una misma tarea rutinaria. La conversión en menos de una generación de miles de habitantes del campo, de pequeños propietarios a obreros industriales y mineros, es lo que la literatura marxista denomina la separación de los trabajadores de sus medios de producción para su posterior proletarización (Perelman, 2000).

Las colonias industriales y mineras fueron en definitiva el modelo de producción dominante del primer capitalismo industrial moderno, si bien es cierto que en el caso de Teruel fueron efímeras y escasos los desarrollos. La mayor parte de la producción textil industrial se realizaba en pequeñas fábricas, que en muchos casos eran ampliaciones de antiguos batanes con varios siglos de historia. La expansión de la industria textil moderna y la paulatina sustitución de la lana omnipresente en Teruel por el algodón importado de las excolonias americanas, y posteriormente tejidos sintéticos fueron el principal factor desarticulador tanto de los batanes que sobrevivían en la provincia, como de la mayor parte de fábricas de lanas. A ello hay que añadir la inestabilidad política que vivió la provincia de Teruel por la Guerra y posguerra civil, periodo en el que numerosas fábricas fueron ocupadas, bombardeadas, cerradas o destruidas. Un ejemplo de pequeña colonia industrial textil sorprendente es el de la Fábrica de Abajo de Nogueruelas, tal y como narra Juan Cervera, conocedor de la industria textil de esta población:

"Durante la guerra bubo aqui un destacamento de republicanos y posteriormente, con la retirada de éstos, del ejército franquista. Asimismo, durante un tiempo fue el refugio para los pacientes del hospital psiquiátrico de Teruel que fueron trasladados hasta aqui por la dureza de la guerra alli, especialmente durante 
la batalla de Teruel. Como temían los bombardeos, excavaron al otro lado del río varias cuevas como refugio en caso de bombardeo, para meter abi a los pacientes y para refugiarse los propios soldados".

[Entrevista].

$\mathrm{Al}$ igual que con los molinos harineros, la creciente concentración de la producción en centros industriales, y posteriormente la crisis de los años setenta, acabaron con el sector textil en la provincia, que en muchas localidades era una actividad con siglos de historia. Tampoco se desplegó en este caso ningún plan o programa de incentivos a la reconversión o modernización. Con la importante crisis económica de esta época y posteriormente la globalización y flexibilización de la producción industrial, el modelo de colonia industrial queda completamente obsoleto y comienzan nuevas olas masivas de éxodo rural dejando cientos de colonias industriales y fábricas completamente abandonadas en muy pocos años, muchas de las cuales continúan en ruina hoy en día (Fabro, 2007).

\subsection{Líneas de actuación propuestas}

Se proponen una serie de líneas de actuación para la protección del patrimonio industrial abandonado disperso de la provincia de Teruel:

- Elaboración de un catálogo o lista de "puntos rojos" que recoja los elementos de patrimonio industrial más valiosos y/o más vulnerables a la degradación o a la desaparición.

- Recopilación a nivel local de la mayor cantidad posible de patrimonio inmaterial en forma de vídeos, audios o transcripciones de los testimonios de la población que construyó, trabajó o vivió en los molinos, fábricas y minas. Dada la edad de muchos de los potenciales informantes esta línea tendría una prioridad muy alta.

- Mayor coordinación entre administraciones locales en la gestión, puesta en valor y difusión del patrimonio industrial. Son demasiado frecuentes los museos o centros de interpretación con escasas actividad y visitas por no haberse concebido según un principio de complementariedad entre varios municipios y no haber establecido una estrategia común que atraiga más visitantes y diversifique la oferta.

- Involucrar mejor a asociaciones y sociedad civil en los proyectos de conservación del patrimonio. En ese sentido puede ser de gran utilidad atraer asociaciones interesadas por el patrimonio minero e industrial, no solo de la provincia, sino a nivel nacional e internacional. También puede ser una vía en ese sentido el firmar pequeños acuerdos de custodia del territorio entre los propietarios y asociaciones o grupos comprometidos en proyectos culturales: uso y gestión del espacio a cambio del mantenimiento y/o rehabilitación. 


\section{Conclusiones}

En los dos últimos siglos, las políticas de Estado económicas y sobre todo de infraestructuras y servicios fueron totalmente favorecedoras a los intereses de las grandes ciudades (Bayo, 1973; Sánchez, 1975; Del Romero, 2018). Pese a que el desarrollo de infraestructuras viarias, de políticas fiscales específicas, o la inversión en I+D es un requisito indispensable para la industria, en el caso de Teruel no se atendió. Cuando ciudades como Valencia ya disponían en los años setenta de modernas autovías de acceso, la provincia de Teruel aun tendría que esperar casi cuatro décadas a la inauguración, en 2008, de la autovía mudéjar. Todo ello contribuiría a la desaparición de la escasa industria que quedaba en la provincia, tras más de un siglo en crisis, agudizando a su vez la crisis demográfica, social y económica ya iniciada en la posguerra, y que atraviesa, aun hoy en día, la provincia de Teruel. Se trata de un territorio que ha sido durante siglos olvidado por las administraciones públicas y que ha adoptado un papel más de suministrador de todo tipo de materias primas (alimentos y minerales básicamente), así como de mano de obra para la industrialización de Barcelona y Valencia, que de desarrollo endógeno diversificado, un esquema muy semejante a las relaciones norte-sur a nivel global.

La efímera y limitada industrialización y protoindustrialización de Teruel ha dejado tras de sí numerosas poblaciones con sociedades desestructuradas, terrenos contaminados, impactos paisajísticos e infraestructuras en desuso. Pero también ha dejado un legado cultural y material de enorme valor, parte del cual está por desgracia olvidado, en ruinas, o en el imaginario colectivo de una parte minoritaria de la población: antiguos mineros, molineros, obreros textiles, maquinistas ferroviarios u oficinistas. Esta es una primera conclusión a extraer de este trabajo: la vasta cantidad de elementos industriales dispersos y abandonados por la geografía rural de la provincia de Teruel. En efecto, el trabajo de campo ha permitido identificar varios centenares de localizaciones que dan muestra de la intensidad de usos industriales y mineros hasta prácticamente mediados del siglo pasado. La mayor parte de los municipios de la provincia tiene algún molino, fábrica, tejería, mina o martinete, generalmente abandonado y del que solo unos pocos conservan memoria de cómo era exactamente, de qué manera funcionaba y cuál era su relevancia en la economía y forma de vida a nivel local e incluso regional. Parte de este legado es ya irrecuperable y en pocos años desaparecerá definitivamente.

Sin embargo otra parte comienza a ser revalorizada y recuperada con fines turísticos, aunque muy limitadamente. Por lo que respecta a las acciones emprendidas para la conservación de este patrimonio, resulta evidente la escasa atención prestada a los elementos dispersos y alejados del centro urbano, especialmente en la poblaciones más pequeñas. Centenares de molinos y otros elementos patrimoniales van quedando progresivamente en ruinas por el abandono y falta de mantenimiento de unos propietarios ausentes, no concienciados o limitados económicamente. Paralelamente, otros elementos patrimoniales son rehabilitados para usos residenciales o turísticos sin respetar 
en muchos casos las morfologías, materiales o estilos tradicionales. Especialmente vulnerables ante las rehabilitaciones poco respetuosas son los elementos de maquinaria, muchas veces funcionales pese a su antigüedad. Más allá de los elementos desmontados, descontextualizados y utilizados como decoración en hoteles o casas, demasiado a menudo es posible encontrar situaciones en los que propietarios o trabajadores dejan expuestos a los elementos y a su destrucción máquinas, estructuras de madera o incluso documentación. El valor del patrimonio industrial de Teruel es merecedor no solamente de un mayor grado de protección, sino de más estudio y difusión con fines turísticos, lúdicos e incluso productivos.

Por último, desde el punto de vista metodológico, un aspecto a destacar, tras la consulta y elaboración de una base de datos sobre industria rural dispersa, es que existe una gran cantidad de información sobre patrimonio industrial, de Aragón en general y de Teruel en particular. No obstante, el formato y grado de detalle de dicha información es muy diverso y disperso. Incluso el SIPCA, que puede considerarse la base de datos de referencia y que se pretende desde la administración que sirva para derivar una base de datos temática sobre patrimonio industrial, presenta algunas deficiencias como la falta de actualización, la identificación errónea de algunos elementos y la falta de inclusión de otros de gran interés.

En ese sentido, la información obtenida a través de entrevistas con propietarios, antiguos molineros, trabajadores de fábricas, artesanos y sus descendientes cercanos resulta vital para que la identificación y caracterización de este patrimonio sea completa y exacta. El patrimonio inmaterial constituido por el testimonio de estas personas puede perderse totalmente en menos de una década por el fallecimiento de muchos de ellos y suele dejarse de lado frente a acciones de conservación de los elementos físicos del patrimonio.

\section{Bibliografía y fuentes}

Archivo Histórico de Provincial de Teruel, 2017. Signatura: O. Sindical 1203/2, 1963.

Asociación de Amigos de Sierra Menera, 2009. El barrio minero de Sierra Menera. La huella gráfica de una vida (1900-1987). Zaragoza, Iberkeltia.

Alquézar, J., 2008. Carbón, franquismo y democracia. En: Alquézar, J. y Rújula, P. (Coord.): Comarca de Andorra-Sierra de Arcos. Zaragoza, Gobierno de Aragón.

Bayo, E., 1973. El manifiesto de la tierra. Barcelona, Planeta.

Bayod Camarero, A., 2009. La expansión de los molinos olearios bajoaragoneses durante los siglos XVI al XVIII. Temas de antropología aragonesa, 15, pp. 71-144.

Benito del Pozo, P., 2002. Patrimonio industrial y cultural del territorio. Boletín de la Asociación de Geógrafos Españoles, 34, pp. 213-228.

Biel Ibáñez, M.P. (coord.). Inventario del patrimonio industrial y la obra pública de Aragón. Inventario inédito, Gobierno de Aragón, Diputaciones y Comarcas, 2004-2009. 
Biel Ibáñez, M.P., 2011. El paisaje de la Electricidad en Aragón. Análisis de algunos casos y propuesta de actuación. Revista electrónica de patrimonio histórico, 8, pp. 1-22.

Biel Ibáñez, M.P., 2012. El patrimonio minero en Aragón. En: J.M. Mata-Perelló (Ed.), 2012, El patrimonio minero y metalúrgico a lo largo de la Historia. Actas del VII Congreso Internacional de minería y metalurgia históricas en el Sudeste Europeo. Utrillas, SEDPGYM, pp. 83-102.

Biel Ibáñez, M.P., 2016. La recuperación de los archivos industriales en Aragón. En: M.A. Ávarez (Ed.), 2016, Archivos, bibliotecas, fototecas de empresas. Fábricas y memoria. Colección Los Ojos de la Memoria, nำ17. Gijón, pp. 565-571.

Biel, M.P., García, M. y Hernández, G., 2008. El patrimonio industrial en la comarca de AndorraSierra de Arcos. En: Alquézar, J. y Rújula, P. (Coord.): Comarca de Andorra-Sierra de Arcos. Zaragoza, Gobierno de Aragón.

Carbonell, V., 2016. Los mases de Estercuel. En: La Contornada, no 25. Centro de Estudios Locales de Andorra. En línea: http://www.celandigital.com/25/index.php/portada/205-contornada/mases/524-mases-gargallo. Consulta: [23-nov.-2017].

Claver, J. y Sebastián, M.A., 2016. Aproximación y propuesta de análisis del patrimonio industrial inmueble español. Madrid, UNED.

Collantes, F., 2004. El declive demográfico en la montaña española (1850-2000). ¿Un drama rural?. Madrid, Ministerio de Agricultura, Pesca y Alimentación.

De Asso y Del Río, I., 1795. Historia de la economía política de Aragón. Zaragoza, https://books.google.es/books?id=3yUOAQAAMAAJEdq=ignacio\%20de\%20asso\%20historia\%20de\%20la

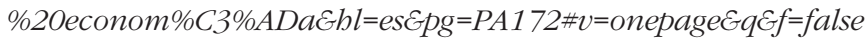

Del Romero, L., 2018. Despoblación y abandono de la España rural. El imposible vencido. Valencia, Tirant lo Blanch.

Diputación Provincial de Huesca, 2017. Sistema de Información sobre el Patrimonio Cultural Aragonés. En línea: http://www.sipca.es/

Fabro Esteban, G., 2007. La estructura económica de la comarca y la minería del carbón, en Alberto Moralejo, Santiago y Royo Lasarte, José (Coords.): Comarca de las Cuencas Mineras. Colección Territorio, 24, Zaragoza, DGA, 2007, pp. 231-248.

Godoy, G., 2014. Las colonias industriales de Catalunya. En línea: http://historiacoloniaindustrialdecatalunya.blogspot.com.es/2014/02/las-colonias-industriales-de-cataluna.html. Consulta: [10-noviembre-2017].

Lozano López, J.C., 1999. Las fábricas de Beceite (Teruel). Artigrama, 14, pp. 109-133.

Muñoz, J., 1978. La inserción de Extremadura en el mercado y su papel de zona dependiente de los intereses en el sistema capitalista. En: VV.AA.: Extremadura saqueada. Recursos naturales y autonomía regional. Madrid: Ruedo Ibérico, pp. 27-34.

Pardo Abad, C.J., 2010. El patrimonio industrial en España: análisis turístico y significado territorial de algunos proyectos de recuperación. Boletín de la Asociación de Geógrafos Españoles, 53, pp. 239-266.

Pardo Abad, C.J., 2016. El patrimonio industrial en España. Madrid, Akal. 
Peiró, A., 2000. Tiempo de industria. Las tierras altas turolenses, de la riqueza a la despoblación. Zaragoza, CEDDAR.

Perelman, M., 2000. The invention of capitalism. Durham, Duke University Press.

Cañizares Ruiz, M.C., 2011. Patrimonio, parques mineros y turismo en España. Cuadernos de Turismo, 27, pp. 133-153.

Salillas, J.M., 2008. Las fábricas textiles y de papel de Villarluengo. Terrassa, Ediciones Radio Terrassa.

Sánchez, J., 1975. La vida rural en la España del siglo XX. Barcelona, Editorial Planeta.

Sanz, S., 2008. La minería en la comarca andorrana. Una perspectiva histórica. En: Alquézar, J. y Rújula, P. (Coord.): Comarca de Andorra-Sierra de Arcos. Zaragoza, Gobierno de Aragón. 
